\title{
Analysis of demand and supply of electrical energy in Cameroon: Influence of meteorological parameters on the monthly power peak of south and North interconnected electricity networks
}

\author{
Flora Isabelle Métégam Fotsing ${ }^{1,2}$, Donatien Njomo ${ }^{1}$, Réné Tchinda ${ }^{2}$ \\ ${ }^{1}$ Environmental Energy Technologies Laboratory (EETL), University of Yaounde I, PO Box 812, Yaounde, Cameroon \\ ${ }^{2}$ Laboratory of Industrial Systemsand Environment of the University of Dschang, PO BOX 96, Dschang, Cameroon \\ Email address: \\ fotsing85@yahoo.fr (I. Fotsing),dnjomo@usa.net (D. Njomo), ttchinda@yahoo.fr (R. Tchinda)
}

To cite this article:

Flora Isabelle Métégam Fotsing, Donatien Njomo, Réné Tchinda. Analysis of Demand and Supply of Electrical Energy in Cameroon: Influence of Meteorological Parameters on the Monthly Power Peak of South and North Interconnected Electricity Networks. International Journal of Energy and Power Engineering. Vol. 3, No. 4, 2014, pp. 168-185. doi: 10.11648/j.ijepe.20140304.12

\begin{abstract}
Following the unbalanced provision between supply and demand of electrical energy in Cameroon, it is necessary to perform an analysis of the data since it can provide essential information for an optimal management of the power supply system. This study presents on the one hand an analysis of electrical energy demand and supply in Cameroon, and, on the other hand, the modeling of the monthly peak of the main interconnected network in Cameroon, namely South Interconnected Networks (RIS) and North (RIN) networks using econometrical methods. Meteorological parameters (monthly maximal temperatures and humidity) are considered as exogenous variables of this application. Following the seasonality observed during various months, the introduction of terms of monthly seasonal as well as an average coefficient Ci peculiar to each month will also be introduced into the linear regression model to evaluate the most suitable one for this modeling. From the above analysis, it appears that meteorological parameters have a significant influence on the monthly peak in both networks. As well as the coefficients of these parameters are not the most significant of the various models, the absence of these parameters in different models leads to an increase Akaike (AIC) and Schwartz (SC) criteria. However, the best model is based on the minimum AIC and SC. The monthly peak in both systems is observed at the same time (20h) and one a working day. This peak may be influenced by other parameters such as the return to households and their consumption pattern, the type of equipment they use amongst other.
\end{abstract}

Keywords: Monthly Peak, Linear Regression Models, Meteorological Parameters, Network RIS and RIN, Modeling, Demand and Supply

\section{Introduction}

Load demand of electricity served by a system of power is not constant in a day; it has maximum values at a given time, which is known as a peak. Electricity was produced and managed in Cameroon till 2013 by an American Company called AES SONEL and since 2014 by an English company called ACTIS. It is produced from three hydroelectric power stations and nine thermal power plants connected to the network. Most of these Thermal power plants are mainly used for the management of the peak (6 to $10 \mathrm{PM}$ ) with the peak observed most of the time at $8 \mathrm{PM}$ and sometime at 7PM. Strong demand during the peak causes decreases the voltage and significant outages that can cause extensive damage to both the population and the economy. In order to reduce the gap between electricity supply and demand, it is necessary to analyze factors that can influence the quantity and quality of demand in order to identify the parameters impacting it heavily.

However, the monthly peak can be influenced by meteorological parameters. Therefore, more information about this monthly peak could help the company that produces the electricity to better manage its means of production. This could also help to advise the government on energy policy to be put in place to meet the population demand of electricity. 
The works presented in this article are intended to analyze and to model the supply and the demand of electricity energy from Cameroon electricity networks. This modeling is based on two types of data, namely the monthly peak consumption and the seasonal variations in meteorological parameters data. However, the specificity of this study results in the quality and variety of sources of supply that meet with many uncertainties, the demand for power consumption. These variations in production affect how Cameroon meets the cyclical demand for its electricity. Different patterns of consumption of electrical energy are thus presented for the two main networks that make the Cameroon electrical park. These models depend in particular on the frequency, the seasonality and the peculiar dynamics of consumption of electricity in the country.

Several studies have been made on the request of the peak load. Reference [17] has implemented strategies to reduce peak demand in southwest deserted region of the United States of America thanks to the cooling load. Reference [7] analyzes the impact of natural light on the peak in Hong Kong. Reference [15] performed an analysis in a residential area in Brazil to satisfy the electricity demand while reducing the peak load. Reference [3] shows that the temperature and seasonality influence the consumption of electricity in Spain. Reference [10] evaluates the influence of economic variables on electricity consumption in Northern Cyprus. Reference [18] analyzes the use of renewable energy in India in order to reduce the load of existing peak. Reference [5] modeled the electricity consumption in Togo using the meteorological parameters as exogenous variables. Reference [21] evaluates the characteristics of the demand of seasonal electricity peak observed in a commercial area in Japan using meteorological parameters as exogenous variables thanks to econometric models.

In this study, we first analyze the demand and supply of electric energy in Cameroon, and then we investigate the monthly peak consumption of the Cameroon major electric networks. The investigations are carried out in the evening because the peak is observed at 8PM in both networks. Seasonal demand patterns are used as a basis for composing the linear regression model. From there, the direct link between the peak load and all the variables in each season can be verified. The typical relationship between seasonal demand peak and the meteorological variables is represented and further analysis carried out on them. The results obtained in this study can give more insight to identify the characteristics between the peak demands and variables that led to it. This research work can contribution to a better operation of power systems. It could become a fundamental work for the seasonal planning decisions necessary to improve the gap between demand and supply during the peak in Cameroon.

This paper is organized as follows; Section 1 presents the analysis of demand in the RIS and RIN; the analysis of supply is presented in Section 2. Data of modeling are described in Section 3. Thereafter, Section 4 presents the various models proposed for the RIS and INR. Section 4 presents the results of regression models. The conclusion and comments are presented in Section 5.

\section{Demand and Supply Analysis in the RIS and RIN}

\subsection{Demand Analysis in the RIS and RIN}

\subsubsection{Demographic Indicators of RIS and RIN}

In the 21 st century, the population of Cameroon is estimated at about 21.7 million inhabitants. Its density is 44.8 inhabitants per $\mathrm{km} 2$ with a natural increase of $2.5 \%$ in 2012 according to World Bank. Cameroon is the most populous country in Central Africa because it has $48 \%$ of the total population of the five countries in this region, followed by Chad (23\%); CAR (11\%); Congo (); Gabon (5\%) and Equatorial Guinea (4\%). Cameroon has a very young population with $42.5 \%$ of young people under age 15 and $19.4 \%$ of residents who are between 24 years and older.

There are three electricity networks to cover the Cameroon space.

- The South interconnected network (RIS): The six areas covered are: Centre, Littoral, West, Northwest, Southwest and South regions.

- The North interconnected network (RIN): it covers three areas: Adamawa, North and Far North regions.

- The Eastern network: this network is not connected; it covers only the East region of Cameroon.

The evolution of the population of the Eastern zone is decreasing due to the under populating caused by a high coverage of the swampy forest. The population of the area of RIN has undergone a light increase from $21.9 \%$ to $34.4 \%$, while the population of the area of RIS has weakly decreased from $66.1 \%$ to $61.9 \%$ between 1976 and 2012. The demographic weight is more pronounced in the Centre region in 2012 with $18.4 \%$, followed by the Far North (18\%) and the Littoral regions (15\%). The causes of this demographic development in the area of RIS can be explained from such factors as the existence of the political and economic capital respectively at the Centre and Littoral regions meanwhile in the area of the RIN it can be justified by a high concentration of the population in the far North region .

In terms of space and knowing the subdivision of Cameroon into ten administrative regions, we note that the demographic weigh is the highest in the Central region (about $18.4 \%$ in 2012), which hosts the political capital Yaoundé, representing an important economic urban center. The other regions also populated are the Far North and the Littoral region with respectively about $18 \%$ and $15 \%$ of the total population of the country in 2012. The Littoral region hosts the main economic center of Cameroon, the city of Douala, with its important commercial sea port which is also a maritime hub in the Central African region. The democratic weights of the Centre and Littoral regions are justified by the relatively high concentration of urban areas 
in these two regions and collective economic and social centers offering employment opportunities. The proportion of the rural population in Cameroon continues to remain significant (48\% in 2010) [2] despite a clear downward trend since 1976. Urbanization rate of the population in Cameroon has however increased from $28.5 \%$ in 1976 to $52 \%$ in 2010 , reflecting a sustained growth of the total urban population, with an average annual growth rate (CAGR) estimated at $4.6 \%$ for the whole period from 1976 - 2010 against $1.5 \%$ average annual growth of the rural population during the same period. Figure 1. shows evolution of the registered demographic distribution in Cameroon by large area.

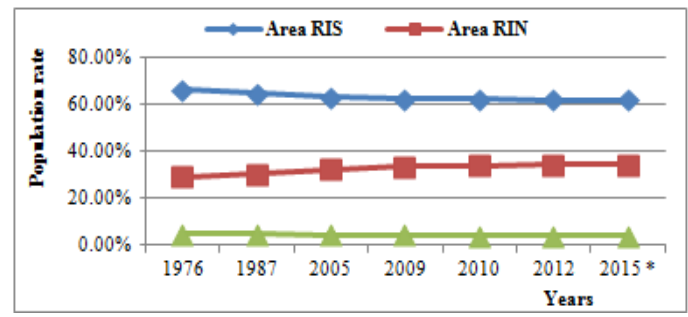

Source: Statistical Yearbook 2010 Cameroon - INS

Figure 1. Evolution of the Registered Demographic distribution in Cameroon by large area

The urbanization rate in various areas is presented as follow: $27.6 \%$ for the NIR, $66 \%$ for RIS and $41.6 \%$ for the RIE [Statistical Yearbook 2010 Cameroon - INS]. In 2010, the global urban population is distributed between the three areas of the country as follow: RIS area $78.7 \%$, RIN area $18 \%$ and RIE area $3.3 \%$. Figure 2 shows evolution of the urbanization rate by region.

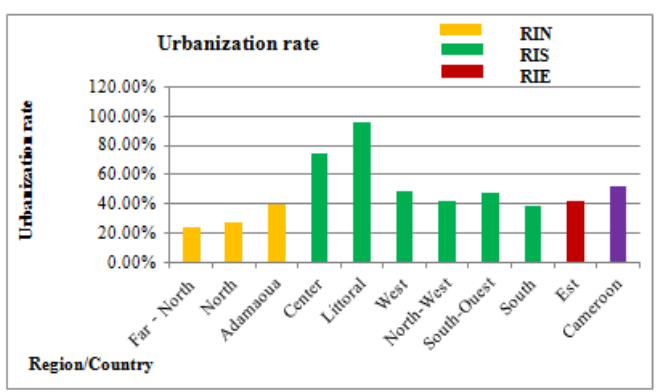

Source: Statistical Yearbook 2010 Cameroon - INS

Figure 2. Evolution of the urbanization rate by region

In terms of poverty, the overall proportion of the Cameroonian population living below the poverty line was estimated in 2007 to about $40 \%$; the index of severity of poverty among the population nationwide has also recorded a decline from $5.6 \%$ in 2001 to $5 \%$ in 2007 . Poverty rate $(\%$ of population living below the poverty line) showed a trend of decrease much more sustained in urban areas than in rural areas, resulting in more job opportunities and more stable incomes in urban areas. According to the available household surveys previously conducted by the INS estimates, the national poverty rate in urban areas has decreased from $44.4 \%$ in 1996 to $12.2 \%$ in 2007 and has reduced in rural areas almost from $60 \%$ in 1996 to $55 \%$ in 2007. Figure 3 shows evolution of registered urbanization rate of the Cameroonian population.

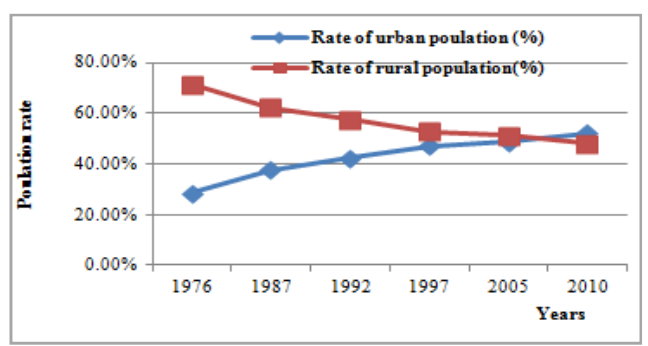

Source: Statistical Yearbook 2010 Cameroon - INS

Figure 3. Evolution of Registered Urbanization rate of the Cameroonian population.

Poverty is more acute in rural areas and especially in the three regions of the RIN region because the income of the population comes mainly from agriculture. This sector is vulnerable to climate hazards, intermittent income it provides and its agricultural techniques have remained traditional and very little mechanized in several regions of the country. Thus, poverty is most prevalent and pronounced in the labor force groups employed in the informal agricultural sector. Those having formal private or administrative activities appear to be less affected by poverty. These activities are more developed in urban areas and in larger socio economic centers of the country, such as Douala and Yaoundé. Taking into account the demographic changes, the average income per capita nationwide is estimated at current prices of 595455.1 FCFA / capita in 2010 and recorded over the last decade (2000-2010) a TCAM of $0,87 \%$.

\subsubsection{Cameroon Macroeconomic Indicators}

Analysis of the structure of real GDP for the year 2009 shows that the tertiary sector (trade, hotels and restaurants, transport and communication, finance \& real estate, administrative services, miscellaneous services) was the main component of the national GDP, estimated at around $47 \%$ share. Activities, Especially business, with catering and hotel industries are the backbone of this sector, with a share of $20.1 \%$ of total national GDP. This can be explained by the low need of investment compared to other economic sectors.

The secondary sector (mining and extraction (including oil activities), manufacturing, construction, electricity, gas \& water) is the second largest economic sector, with an estimated share of nearly $30 \%$ of real GDP in 2009 . The manufacturing industries represent the sub prime sector with a contribution to the national GDP of about $16 \%$, estimated in the same year.

The primary sector (agriculture, forestry and forest extraction, fishing, hunting and livestock) has meanwhile accounted for less than one quarter of national GDP at a constant price, nearly $23 \%$ in 2009 . Primary key sub-sector 
is subsistence agriculture which would have been $63 \%$ of GDP the same year around against respectively $13 \%$ for forestry, $12 \%$ for livestock \& hunting, $6.5 \%$ for industrial agriculture and exports and $5.5 \%$ for fishing. [23]. Figure 4. shows evolution of sectorial GDP and average annual growth rate.

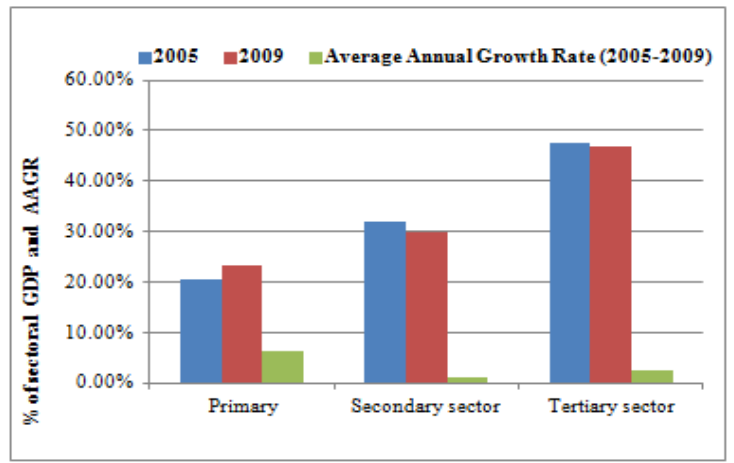

Figure 4. Evolution of sectorial GDP and $A A G R$

\subsection{Analysis of Supply}

\subsubsection{Electric Power Generation}

The electricity generation fleet managed by AES SONEL has three hydroelectric plants, two of them feed the South network (RIS) and 9 thermal plants connected to the grid, including eight (8) debiting on the RIS. At the end of 2011, one could count 26 isolated plants, which 12 built in the regions supplied by the RIS, 8 in the northern areas served by the north network (RIN) and the 6 remaining others were established in the area of East network (eastern region); by analogy to RIN and RIS, the latter will be designated by RIE, especially as it is expected to have a supply of $90 \mathrm{kV}$ from the Lom Pangar dam as from 2016. Thus, over $56 \%$ of the workforce electric park is concentrated in the large area of the South (RIS area), with $83 \%$ of the main stations connected to the network and $44 \%$ of isolated plants; this therefore should reflect the relative importance of the electricity demands in the Great South network. Table 1 shows the electric energy production (in $\%$ of total production).

Table 1. Electric Energy Production (in\% of Total Production)

\begin{tabular}{|c|c|c|c|c|c|c|c|c|}
\hline Year /Electric Production & 2005 & 2006 & 2007 & 2008 & 2009 & 2010 & 2011 & Average share \\
\hline Hydro - RIS & $89,00 \%$ & $88,70 \%$ & $85,20 \%$ & $89,00 \%$ & $84,80 \%$ & $86,50 \%$ & $86,30 \%$ & $87,10 \%$ \\
\hline Hydro- RIN & $5,20 \%$ & $5,10 \%$ & $5,10 \%$ & $4,90 \%$ & $5,40 \%$ & $5,40 \%$ & $5,40 \%$ & $5,20 \%$ \\
\hline Hydro- (RIN+RIS) & $94,20 \%$ & $93,80 \%$ & $90,40 \%$ & $93,90 \%$ & $90,20 \%$ & $91,90 \%$ & $91,70 \%$ & $92,30 \%$ \\
\hline Thermal- RIS & $4,50 \%$ & $4,80 \%$ & $8,30 \%$ & $4,40 \%$ & $8,10 \%$ & $6,30 \%$ & $6,50 \%$ & $6,10 \%$ \\
\hline Thermal - RIN & $2,9 \%{ }^{\circ}$ & $0,2 \%{ }^{\circ}$ & & $0,1 \%{ }^{\circ}$ & $0,1 \%{ }^{\circ}$ & & & $\begin{array}{l}0,8 \%{ }^{\circ} \\
\text { (per thousands) }\end{array}$ \\
\hline Total Thermal (RIN+RIS) & $4,50 \%$ & $4,80 \%$ & $8,30 \%$ & $4,40 \%$ & $8,10 \%$ & $6,30 \%$ & $6,50 \%$ & $6,10 \%$ \\
\hline Total Hydro + Thermal RIS & $93,50 \%$ & $93,50 \%$ & $93,50 \%$ & $93,50 \%$ & $92,9 \%$ & $92,80 \%$ & $92,80 \%$ & $93,20 \%$ \\
\hline Total Hydro + Thermal RIN & $5,20 \%$ & $5,10 \%$ & $5,10 \%$ & $4,90 \%$ & $5,50 \%$ & $5,40 \%$ & $5,40 \%$ & $5,20 \%$ \\
\hline Total Hydro + Thermal (RIN+RIS) & $98,70 \%$ & $98,60 \%$ & $98,60 \%$ & $98,40 \%$ & $98,30 \%$ & $98,20 \%$ & $98,20 \%$ & $98,40 \%$ \\
\hline Total isolated Thermal - RIS & $0,15 \%$ & $0,16 \%$ & $0,17 \%$ & $0,18 \%$ & $0,16 \%$ & $0,19 \%$ & $0,21 \%$ & $0,20 \%$ \\
\hline Total isolated Thermal - RIE & $0,73 \%$ & $0,77 \%$ & $0,74 \%$ & $0,84 \%$ & $0,94 \%$ & $0,96 \%$ & $1,05 \%$ & $0,90 \%$ \\
\hline Total isolated Thermal - RIN & $0,41 \%$ & $0,44 \%$ & $0,38 \%$ & $0,49 \%$ & $0,55 \%$ & $0,53 \%$ & $0,53 \%$ & $0,50 \%$ \\
\hline $\begin{array}{l}\text { Total isolated Thermal } \\
\text { (RIN+RIS+RIE) }\end{array}$ & $1,30 \%$ & $1,40 \%$ & $1,40 \%$ & $1,60 \%$ & $1,80 \%$ & $1,80 \%$ & $1,80 \%$ & $1,60 \%$ \\
\hline overall & $100,00 \%$ & $100,00 \%$ & $100,00 \%$ & $100,00 \%$ & $100,00 \%$ & $100,00 \%$ & $100,00 \%$ & $100,00 \%$ \\
\hline
\end{tabular}

Source: AES SONEL

Hydro electric production accounted for the bulk of domestic production, with over an average of $92 \%$ of national electric production managed by AES SONEL from 2005 to 2011. The predominant share of electricity produced by AES SONEL, with an averaging of $87.1 \%$ is located in the regions supplied by the RIS. The share of thermal generation plants connected to the grid represented an average of $6.1 \%$ of the production of AES SONEL nationwide during the last period, with a maximum of $8.3 \%$ obtained in 2007. Isolated thermal power plants yield, in turn, an average of $1.6 \%$ of the national production of AES SONEL, with a maximum of $1.8 \%$ in 2011 [1]. Isolated plants that have been dismantled had yield roughly a share of about $0.046 \%$ on average of the total domestic production.

\subsubsection{Non-Synchronous Peak Output}

Over the period 2005-2011, The sum of the peaks from the three hydro electric represents an average of $82.3 \%$ of the total peaks of all power plants connected to the grid, with a maximum of $85.2 \%$ in 2011 and a minimum of $803 \%$ in 2005 . The share of thermal power plants connected to the grid represents during the same period an average of $17.7 \%$ of the total sum of peaks recorded, with a minimum of $14.8 \%$ in 2011 and a maximum of $197 \%$ in 2010 . From the above, we see that the share production of heat from thermal power plants has been steadily declining over the same period in favor of hydroelectric generation which grew $5 \mathrm{MW}$ over the same period. As previously checked, these grid-connected power plants produce an average of $6.1 \%$ of the total energy produced by AES SONEL, confirming the 
supporting role in peak power plants connected to the AESSONEL grid. Most of the power plants contribute much to the national forefront, with the exception of the LPP (Limbe Power Plant) which, alone, produces $10.1 \%$ of $17.7 \%$ representing the total contribution of thermal plants connected to network. Table 2 shows power peak observed by central (in MW).

Table 2. Power Peak Observed by Central (in MW)

\begin{tabular}{|c|c|c|c|c|c|c|c|}
\hline Years/ Peak & 2005 & 2006 & 2007 & 2008 & 2009 & 2010 & 2011 \\
\hline Hydro- RIS & 563 & 588 & 603 & 632 & 633 & 655 & 646 \\
\hline Hydro - RIN & 40,4 & 40,6 & 41,7 & 40,1 & 45,2 & 46 & 48,9 \\
\hline Total Hydro- (RIN+RIS) & 603 & 629 & 645 & 672 & 678 & 701 & 695 \\
\hline Thermal - RIS & 148 & 149 & 148 & 136 & 157 & 128 & 121 \\
\hline Thermal - RIN & 0 & 4,1 & 0 & 1,1 & 0,9 & & \\
\hline Total Thermal (RIN+RIS) & 148 & 149 & 148 & 137 & 157 & 128 & 121 \\
\hline Total Hydro+ Thermal - RIS & 711 & 737 & 751 & 768 & 790 & 783 & 767 \\
\hline Total Hydro. + Thermal - RIN & 40 & 45 & 42 & 41 & 46 & 46 & 49 \\
\hline Total Hydro + Thermal (RIS+RIN) & 751 & 782 & 793 & 809 & 836 & 829 & 816 \\
\hline Totale Isolated Thermal- RIS & $*$ & $*$ & 3,24 & 2,58 & 2,45 & 2,33 & 2,74 \\
\hline Total Thermal Isolée - RIE & $*$ & $*$ & 8,05 & 8,63 & 9,44 & 10,51 & 11,50 \\
\hline Total Isolated Thermal - RIN & $*$ & $*$ & 4,43 & 5,00 & 5,63 & 5,04 & 5,39 \\
\hline $\begin{array}{l}\text { Total Isolated Thermal } \\
\text { (RIN+RIS+RIE) }\end{array}$ & $*$ & $*$ & 16,27 & 26,79 & 18,18 & 17,88 & 19,63 \\
\hline overall & & & 809 & 835 & 854 & 847 & 836 \\
\hline
\end{tabular}

Source: AES SONEL * Data not shown

Table 3. Determination of Synchronous peaks from RIS and RIN Networks (January 2006 - May 2012)

\begin{tabular}{|c|c|c|c|c|c|c|c|c|}
\hline \multicolumn{2}{|c|}{ Years } & 2006 & 2007 & 2008 & 2009 & 2010 & 2011 & 2012 \\
\hline \multicolumn{9}{|c|}{ N RIS Network } \\
\hline 1 & Peak RIS (MW) & 490,4 & 514 & 555 & 584,8 & 616,3 & 666,84 & \\
\hline 2 & $\begin{array}{l}\text { Annual increment } \\
\text { per cent }(\%)\end{array}$ & & $4,8 \%$ & $8,0 \%$ & $5,4 \%$ & $5,4 \%$ & $8,2 \%$ & \\
\hline 3 & Date of peak & $\begin{array}{l}26^{\text {th }} \text { Dec. } \\
\text { (Tuesday) }\end{array}$ & $\begin{array}{l}27^{\text {th }} \text { Dec. } \\
\text { (Thursday) }\end{array}$ & $\begin{array}{l}24^{\text {th }} \text { Dec. } \\
\text { (Wednesday) }\end{array}$ & $\begin{array}{l}17^{\text {th }} \text { Dec. } \\
\text { (Thursday) }\end{array}$ & $\begin{array}{l}16^{\text {th }} \text { Dec. } \\
\text { (Thursday) }\end{array}$ & $\begin{array}{l}9^{\text {th }} \text { Dec. } \\
\text { (Friday) }\end{array}$ & \\
\hline 4 & time of peak & 08PM & 08PM & 08PM & 08PM & 08PM & 08PM & \\
\hline 5 & $\begin{array}{l}\text { Load of RIN synchronous with } \\
\text { annual peak of RIS (in MW) }\end{array}$ & 35,4 & 32,2 & 34,0 & 37,4 & 40,0 & 42,3 & \\
\hline 6 & $\begin{array}{l}\text { Sum of synchronous loads of RIS } \\
+ \text { RIN with the peak RIS }\end{array}$ & 525,8 & 546,2 & 589,0 & 622,2 & 656,3 & 709,1 & \\
\hline 7 & Annual increment per cent $(\%)$ & & $3,9 \%$ & $7,8 \%$ & $5,6 \%$ & $5,6 \%$ & $8,1 \%$ & \\
\hline \multicolumn{9}{|c|}{ RIN Network } \\
\hline 8 & Peak RIN (MW) & 39,8 & 40,5 & 39,3 & 44,4 & 45 & 49 & 51,5 \\
\hline 9 & Annual increment per cent $(\%)$ & & $1,8 \%$ & $-3,0 \%$ & $13,0 \%$ & $1,4 \%$ & $8,9 \%$ & $5,1 \%$ \\
\hline 10 & Date of peak & $\begin{array}{l}23^{\mathrm{h}} \text { Feb. } \\
\text { (Thursday) }\end{array}$ & $\begin{array}{l}07^{\mathrm{h}} \text { Mach } \\
\text { (Wednesday) }\end{array}$ & $\begin{array}{l}06^{\mathrm{h}} \text { Mach } \\
\text { (Thursday) }\end{array}$ & $\begin{array}{l}23^{\mathrm{h}} \text { Mach } \\
\text { (Monday) }\end{array}$ & $\begin{array}{l}17^{\mathrm{h}} \text { Feb. } \\
\text { (Wednesday) }\end{array}$ & $\begin{array}{l}25^{\mathrm{h}} \text { Mach } \\
\text { (Wednesday) }\end{array}$ & $\begin{array}{l}13^{\mathrm{h}} \text { Mach } \\
\text { (Tuesday) }\end{array}$ \\
\hline 11 & time of peak & 08PM & 08PM & 08PM & 08PM & 08PM & 08PM & 08PM \\
\hline 12 & $\begin{array}{l}\text { Load of RIS synchronous with } \\
\text { annual peak of RIN (in MW) }\end{array}$ & 426,7 & 491,8 & 502,0 & 494,1 & 552,2 & 578,3 & 582,9 \\
\hline 13 & $\begin{array}{l}\text { Sum of synchronous loads of } \\
\text { RIS + RIN with the peak RIN }\end{array}$ & 466,5 & 532,3 & 541,3 & 538,5 & 597,2 & 627,3 & 634,4 \\
\hline 14 & Annual increment per cent $(\%)$ & & $14,1 \%$ & $1,7 \%$ & $-0,5 \%$ & $10,9 \%$ & $5,0 \%$ & $1,1 \%$ \\
\hline \multicolumn{9}{|c|}{ RIN + RIS Networks } \\
\hline 15 & $\begin{array}{l}\text { Sum (Non synchronous) of } \\
\text { individual peaks of the two } \\
\text { RIS \&RIN networks of the } \\
\text { same year (in MW) }\end{array}$ & 530,2 & 554,5 & 594,3 & 629,2 & 661,3 & 715,8 & \\
\hline \multicolumn{9}{|c|}{ Sum of non synchronous /synchronousSomme peaks } \\
\hline 16 & Coefficient of de expansion & 0,992 & 0,985 & 0,991 & 0,989 & 0,992 & 0,991 & \\
\hline
\end{tabular}

Source: Load curves collected AES-SONEL from 2006 to May 2012 


\subsubsection{Comparison between Non-Synchronous Sum of Peaks and the Synchronous Peak of Each RIN and RIS Networks}

The analysis of load curves from 2006 to 2011 and the first term of 2012 enable us to identify and assess the synchronous peak of production centers connected to each RIN and RIS systems, considered separately. The aggregation of load curves enables to determine the overall synchronous peak of the two RIS RIN networks. This aggregation allows us to estimate the expansion coefficients. Table 2.3 summarizes the results of this analysis. The values shown in this table derive from the analysis of load curves received from AES-SONEL on both RIN and RIS networks.

The annual peak of RIS network always takes place over the period studied, the month of December, a working day to 20 hours. This peak has evolved with an average Annual increment percentage of $6.3 \%$. The synchronous network load of RIN with the annual peak of the RIS (same year, same day and same time) was determined and the synchronous sum in MW of the two networks at the forefront of RIS was calculated on lines 5 and 6 of Table 3.

The increment of this sum has evolved with an average rate of $6.2 \%$; a number close to that of RIS considered alone, given the importance of its load. This sum would have been the synchronous global peak of both RIS and RIN networks if they were interconnected.

The annual peak of the RIN is offset in time from two to three months compared to the RIS. It took place on the same period, twice in the month of February, but most often it occurs in March, a working day by 8PM. This peak has evolved at an average rate of $4.5 \%$ per annum. The load synchronous in the RIS with the annual peak of the RIN (same year, same day and same time) was determined and the amount of synchronous MW of the two networks at the forefront of RIN was calculated (see 12 and 13). The Increment of the synchronous sum has evolved at an average rate of $5.4 \%$. This sum would have been the global synchronous peak of the two RIS and RIN networks during the period from February to March if they were interconnected. Based on the overall load synchronous with the peak of RIS end of previous year (n-1), calculation shows that if the low water period allowed, the power available to the peak of the RIN (February - March) of the year "n" would enable a transfer of power from the RIS to the RIN during the peak of the RIN of the same year. This assignable power is variably carried on from one year to another, between 4.9 MW (2008) and 74.7 MW (2011); Except in 2007 during which the sum of the loads of the two synchronous networks exceeded that obtained at the forefront of December 2006 (three months earlier) in March.

Line 15 of Table 3 presents the sum of the individual non-synchronous peaks of the two networks. The comparison between the non-synchronous sum of the individual peaks (see line 15) to the highest synchronous peak of December (see line 6) gives an expansion coefficient of 0.99. A coefficient of expansion can be considered as the ratio between (i) the sum of synchronous loads of the two networks at the forefront of RIS in a given year and (ii) non-synchronous sum of the two individual peaks of the same year ( see line 16 of Table 2.3). This coefficient helps to predict, if the northern and southern networks were interconnected, a global synchronous peak of the two networks by multiplying the sum of the individual peaks of the two networks for the same year by this coefficient.

\subsubsection{Duration of use of the Peak at the Central}

The calculations were carried out by using the energy produced at each plant the annual peak of the plant. The duration of use calculated for each unit enables to convert the energy produced by a power plant (MWh) into the peak power (in MW).

Table 4. Calculation of the duration of the use of the peak (hours / year) - thermal and hydroelectric power plants connected to the network and isolated plants

\begin{tabular}{lllllllll}
\hline Years/ duration of use & $\mathbf{2 0 0 5}$ & $\mathbf{2 0 0 6}$ & $\mathbf{2 0 0 7}$ & $\mathbf{2 0 0 8}$ & $\mathbf{2 0 0 9}$ & $\mathbf{2 0 1 0}$ & $\mathbf{2 0 1 1}$ & Average \\
\hline Hydro - RIS & 6340 & 6258 & 6018 & 6346 & 5968 & 6119 & 6405 & 6208 \\
Hydro- RIN & 5117 & 5222 & 5229 & 5538 & 5274 & 5447 & 5314 & 5306 \\
Total Hydro- (RIN + RIS) & & 6191 & 5967 & 6297 & 5922 & 6075 & 6328 & 6148 \\
Thermal - RIS & 1226 & 1323 & 2388 & 1474 & 2296 & 2288 & 2582 & 1939 \\
Thermal - RIN & $*$ & 2 & $*$ & 5 & 4 & $*$ & $*$ & 4 \\
Total Thermal (RIN + RIS) & 1227 & 1288 & 2388 & 1462 & 2283 & 2288 & 2582 & 1931 \\
Total (Hydro + Thermal) RIS & 5277 & 5261 & 5304 & 5485 & 5240 & 5494 & 5801 & 5409 \\
Total (Hydro + Thermal) RIN & 5120 & 4743 & 5229 & 5390 & 5171 & 5447 & 5314 & 5202 \\
Total (Hydro+ Thermal) (RIS+RIN) & 5268 & 5231 & 5300 & 5481 & 5237 & 5491 & 5772 & 5397 \\
Totale Isolated Thermal Isolée - RIS & $*$ & $*$ & 2247 & 3116 & 2836 & 3754 & 3700 & 3131 \\
Totale Isolated Thermal - RIE & $*$ & $*$ & 3918 & 4402 & 4433 & 4223 & 4392 & 4274 \\
Totale Isolated Thermal- RIN & $*$ & $*$ & 3625 & 4374 & 4382 & 4892 & 4688 & 4392 \\
Total Isolated Thermal (RIN + RIS+RIE) & $*$ & $*$ & 3586 & 4353 & 4327 & 4467 & 4377 & 4222 \\
Total Nationwide & 5268 & 5231 & 5266 & 5458 & 5218 & 5469 & 5739 & 5379 \\
\hline
\end{tabular}

Source: AES SONEL * Data not shown 
Inspection of Table 4 shows that the life of the hydro is much higher than that of thermal power plants. The overall averages in hours of operation are as follow:

- Hydroelectric power plants: 6,148 h / year (with a higher average for Edea plant i.e $6929 \mathrm{~h} /$ year)

- Thermal power stations connected to the network: $1931 \mathrm{~h} /$ year

- Hydroelectric power and thermal plants connected: $5397 \mathrm{~h} /$ year

- $\quad$ isolated thermal power plants: $3910 \mathrm{~h} /$ year

- Global Production (plants only managed by AES SONEL): $5417 \mathrm{~h} /$ year

Note that the utilization factor is the life of the peak relative to the number of hours of the year that is 8760 hours.

\section{Data Modeling}

Two types of data have been used for modeling the demand for electrical energy in Cameroon: meteorological data and monthly electricity peak of RIS and RIN networks.

\subsection{Rate of Electricity Coverage in Different Networks}

In 2007, the lowest covered region in electricity was the Far North, while the highest coverage rate was recorded in the South. Figure 5 shows rate of access to electricity and poverty index by region.

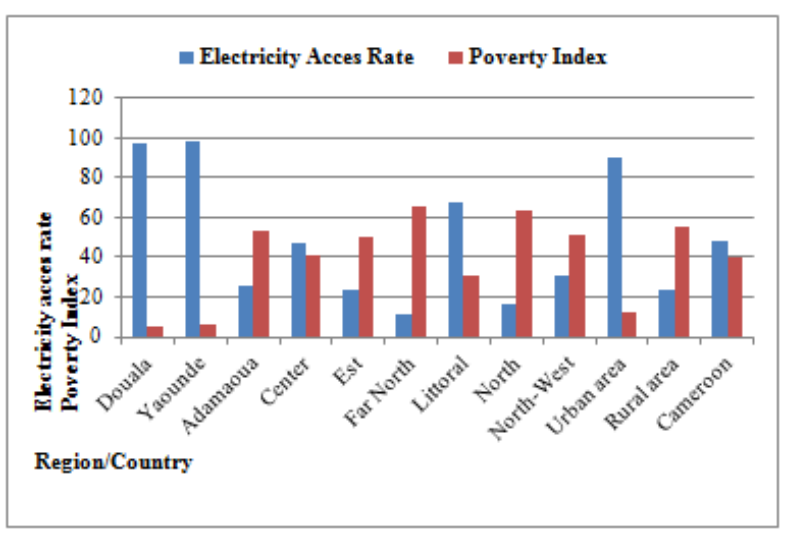

Figure 5. Rate of access to electricity and poverty index by region.

Agglomerations of Yaoundé and Douala have the most beneficial coverage rate. For these regions, this rate of coverage had an average of $48.3 \%$ in the same year and proved to be 3.9 times higher in urban than in rural areas. The poorest regions, with the most critical poverty index appeared to be underserved in electrical energy. These regions were: the Great Northen regions (far North and North) and East region. This reflects the social and human issue required for the spatial coverage of the electrical service in these regions. Meteorological parameters used are those of Douala and Ngaoundere respectively for the RIS and INR. When considering the peak power of stations, the most important are located in the Littoral region where the head quarter is Douala. In 2010, it alone concentrated
$46 \%$ of the total peak of RIS. This is due to the fact that Douala is the economic capital; therefore, it has a high concentration of population and industries. According to the statistics of sales of electricity produced by AES SONEL, these two regions consume the greater part of energy of each of the networks. Moreover, the access to electricity is higher in Ngaoundere than in other regions of the RIN. This is why we use meteorological parameters of Douala and Ngaoundere as characteristic for the modeling of the monthly peaks of RIS and RIN respectively.

\subsection{The Influence of Meteorological Parameters on the Monthly Peak Electricity Consumption}

We looked particularly into the maximal temperature, the minimal relative humidity of each month because of their potential influence on the electrical energy consumption. These parameters reflect the interchange of rainy and dry seasons, which are the major climatic events in Cameroon. Meteorological data are obtained from the Meteorological Service of the Ministry of Transport. We did not succeed to obtain the data on the relative humidity in the Ngaoundere (RIN) during the period from 2006 to 2011 because they were not available, thus we only used data from the temperature in this area for modeling.

$\mathrm{n}$ has variations on the climate map. A dry season goes from November to February, followed by a short rainy season from March to June, then a big rainy season from August to late September in the South of the country. The average temperature is $26^{\circ}$. In the north, the rainy season goes from May to September. The average of the temperature in the Far North is $29^{\circ} \mathrm{C} ; 22^{\circ}$ in Adamaoua. However, it should be noted that the month of August in the North is the season of heavy rains and the month of March is characterized by high temperatures. In general, thermal amplitudes vary from $7^{\circ}$ to $40^{\circ} \mathrm{C}$ between January and December.

In the area of RIS, we have the following regions with their latitude and longitude: Yaoundé $\left(3^{\circ} 52^{\prime} \mathrm{N} 11^{\circ} 32^{\prime} \mathrm{E}\right.$, Centre), Douala $\left(04^{\circ} 00^{\prime} \mathrm{N}, 0^{\circ} 45^{\prime} \mathrm{E}\right.$., the Littoral), Bafoussam $\left(5^{\circ} 28^{\prime} \mathrm{N}, 10^{\circ} 25^{\prime} \mathrm{E}\right.$ in the West), Buea $\left(4^{\circ} 09^{\prime} 09^{\prime \prime}\right.$ N, 9०14'27" E, South West), Bamenda (5 $56^{\prime} \mathrm{N}, 10^{\circ} 1^{\prime} \mathrm{E}$ North West), Bertoua (4.58333N ,13.6833E, in the East), Bamenda $\left(8^{\circ} 59^{\prime} \mathrm{N}, 1^{\circ} 09^{\prime} \mathrm{E}\right.$, North West $)$, South $\}$. In the area of RIN, we have the following regions with their longitude and latitude: (Maroua $\left(10^{\circ} 50^{\prime} 14.28\right.$ "N, $14^{\circ}$ $55^{\prime} 24$.39" E., in the extreme south), Garoua $\left(9^{\circ} 18^{\prime} 00^{\prime \prime} \mathrm{N}\right.$, $13^{\circ} 24^{\prime} 00^{\prime \prime} \quad \mathrm{E}, \quad$ North), Ngaoundere $\left(13^{\circ} 35^{\prime} 7.19^{\prime \prime} \mathrm{E}\right.$, $7^{\circ} 12^{\prime} 33.35^{\prime \prime} \mathrm{N}$, in the Adamawa). We use in this paper the data measured in Douala for RIS and in Ngaoundere for RIN. 


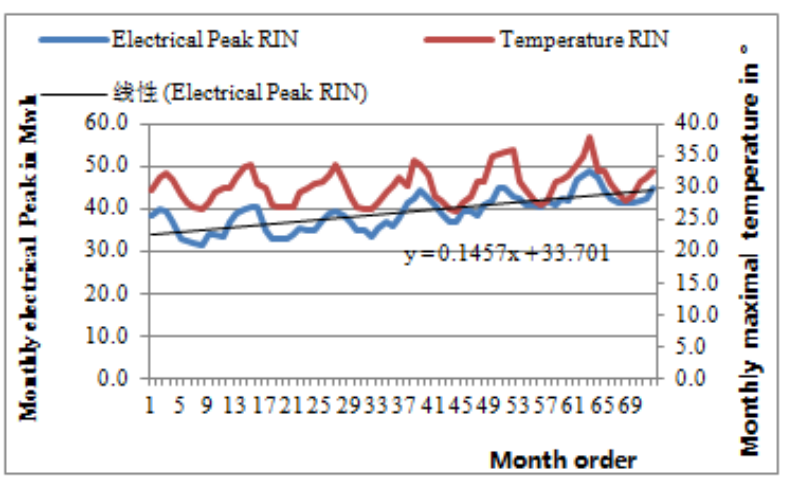

(a)

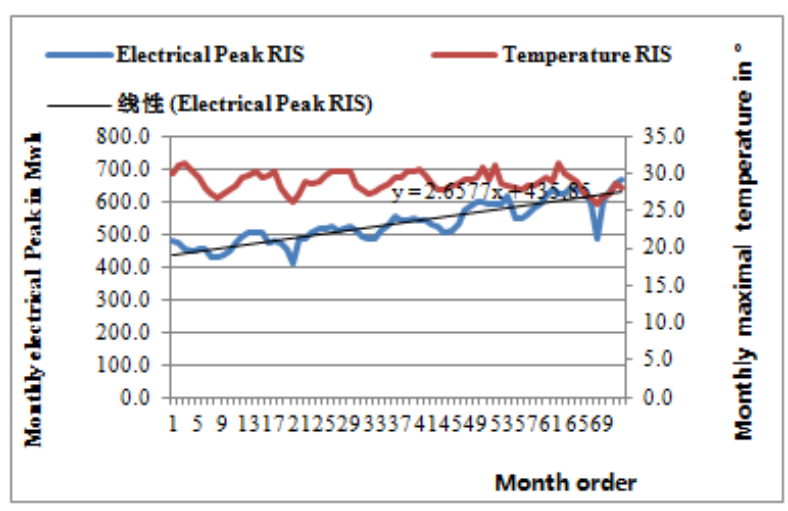

(b)

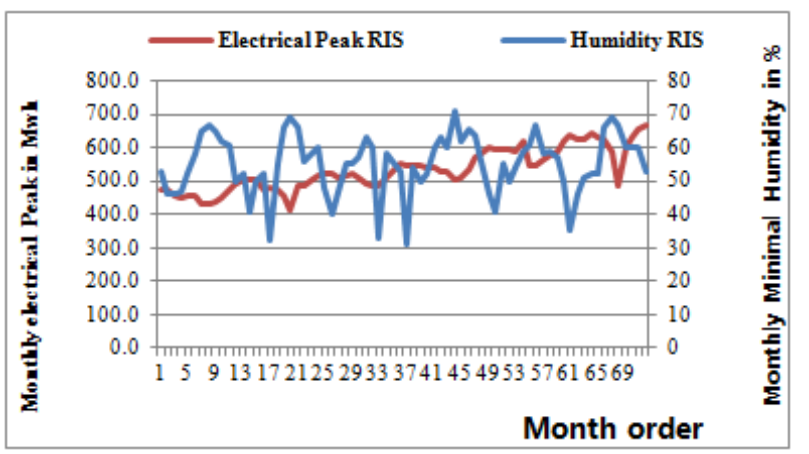

(c)

Figure 6. Evolution of the monthly peak power, maximal and minimal temperature and relative humidity in the RIS and the RIN Networks.

Figure 6. shows the evolution of monthly values of relative humidity and temperature in Douala and Ngaoundere from January 2006 to December 2011. Abscissa, the number 1 is the first month of our data base (January $2006=1$, February $2006=2$, December 2011= 72). The overall observation of this figure shows a high level of humidity of above $57 \%$ in the RIS. The temperatures below this threshold reflect the impact of the dry season. It is also observed at the same instants the maximum temperatures of above $28^{\circ}$ and $32^{\circ}$ respectively in the RIS and RIN reflecting the effect of the dry season too.

For this study, our sample consists of 72 measures (12 measures per year for six years). The evolution of electric power in Cameroon, reported in Figure 3.2 shows an increasing trend in the average electricity consumption, added to annual quasi-periodic features. The extrapolation of a linear trend used to evaluate the annual growth rate of energy consumption to about $7 \%$.

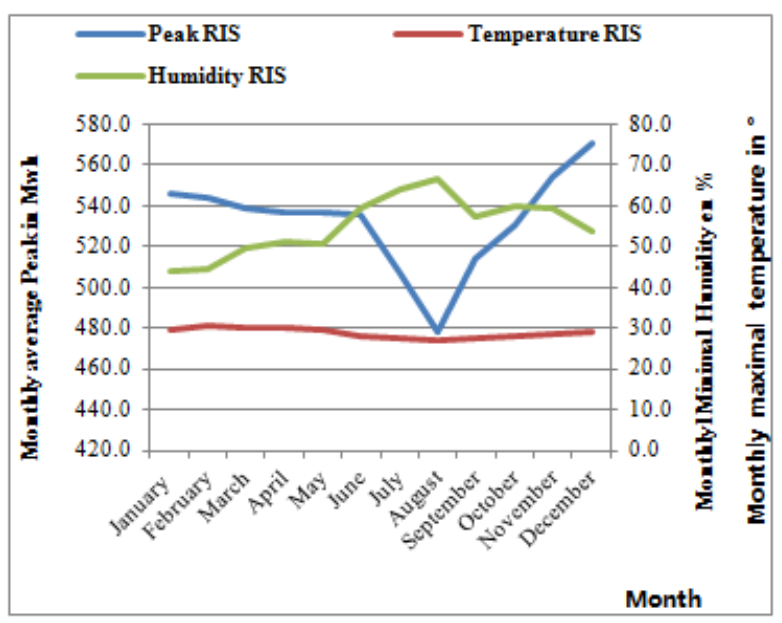

(a)

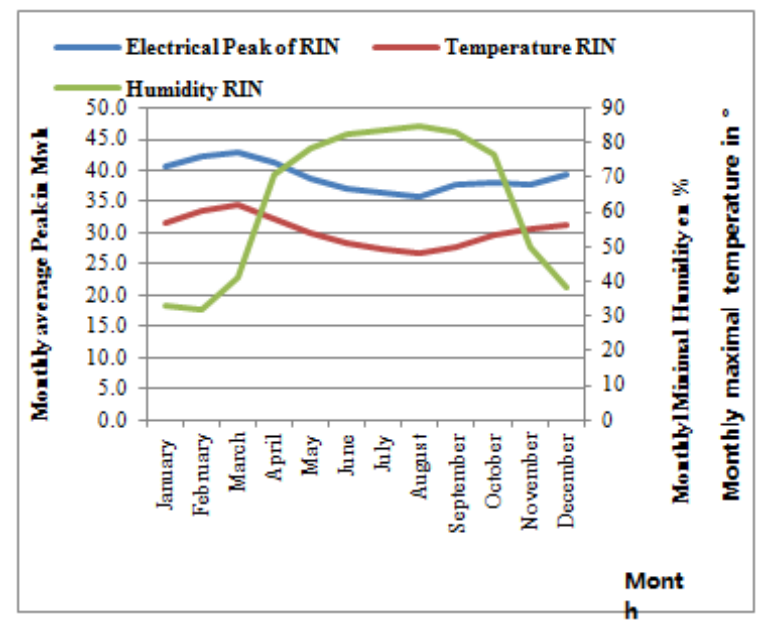

(b)

Figure 7. Profiles normalized peak power, temperature and humidity for the RIS and RIN

Meteorological data, like electrical data peak present seasonal patterns. So there are annual profiles of the electrical peak and profiles of meteorological parameters variations. In Figure 7, normalized profiles of monthly electrical peak, of temperature and humidity are presented. It makes us distinguish the following main properties:

- The existence of electrical peaks during the month $\mathrm{N}^{\circ} 2$ and 3 in the RIN and $\mathrm{N}^{\circ} 12$ in the RIS (February and March in RIN and December in RIS).

- The existence of a minimum of electrical consumption during the month No. 8 (August) for RIS and RIN.

- The maximum of electrical consumption corresponds to the maximum of temperature

- The temperature variations are in phase opposition with the relative humidity.

- The annual electrical peak corresponds to the 
maximum of temperature and the minimum of humidity. These moments are representative of the dry season, more adequate to a high electrical consumption.

\section{Methodology}

\subsection{General}

A time series is a set of observations that are distinguished by the important role that the order in which they were collected plays .The principal models for the study of time series are:

- $\quad$ Autoregressive models ("Auto - Regressive ").

They were introduced by Yule [24]. In these models, we take into account a linear dependence of the process of its own lag.

$$
X_{t}=\alpha_{1} X_{t-1}+\alpha_{2} X_{t-2}+\cdots+\alpha_{p} X_{t-p}+u_{t}
$$

Where $\mathrm{p} \in \mathrm{N} *$ is the order of the process, $\alpha_{1}, \alpha_{2}, \ldots \alpha_{p}$ are real constants and $\left(u_{t}\right)_{\mathrm{t} Z \mathrm{Z}}$ is white noise .

- Moving average models («Moving Average»)

- $\quad$ They were introduced by Slutsky [24]. A moving average process is the sum of white noise and its past:

$\operatorname{MA}(\mathrm{q}): X_{t}=u_{t}+\beta_{1} u_{t-1}+\beta_{2} u_{t-2}+\cdots+\beta_{p} u_{t-q}$

Where $\mathrm{q} \varepsilon \mathrm{N} *$ and $\beta_{1}, \beta_{2}, \ldots \beta_{p}$ are real constants .

- ARMA models ("Auto - Regressive Moving Average")

- Developed by Box \& Jenkins [Box \& Jenkins, 1970]. ARMA models are a combination of autoregressive and moving average models:

ARMA (p, q) : $X_{t}-\alpha_{1} X_{t-1}-\alpha_{2} X_{t-2}-\cdots-$ $\alpha_{p} X_{t-p}=u_{t}+\beta_{1} u_{t-1}+\beta_{2} u_{t-2}+\cdots+\beta_{p} u_{t-q}$

- The ARIMA (Autoregressive Integrated Moving Average) and SARIMA (Seasonal Autoregressive Integrated Moving Average) (a SARIMA process is an integrated ARMA process with seasonal component) [Box \& Jenkins in, 1970].

ARIMA and SARIMA models were then developed in order to model a large number of real phenomena that present trends and / or seasonality. ARMA models are applied to integrated series.

Linear regression is a statistical technique used to model the linear relationship between exogenous variables (denoted $Y_{i t}$ ) and an endogenous variable (denoted by $X_{t}$ ).

$$
X_{t}=\alpha_{0}+\alpha_{1} X_{t-1}+\alpha_{2} Y_{1 t}+\alpha_{3} Y_{2 t}+\cdots+\alpha_{n} Y_{n t}+u_{t}
$$

Where:

- $X_{t}$ Is the variable to be explained in our article, which is monthly electrical peak

- $X_{t-1}$ is the lag value for the monthly electrical peak

- $Y_{i t}$ The exogenous variables (temperature (T), relative humidity $(\mathrm{H})$, Order of the month $(\mathrm{M})$ )

$\alpha_{0}, \alpha_{1}, \ldots \alpha_{n}$ are the parameters to estimate from the model.

$u_{t}$ is the white noise defined by the relation :

$$
u_{t}=\beta_{1} u_{t-1}+\beta_{2} u_{t-2}+\ldots+\beta_{P} u_{t-P}+\varepsilon_{t}
$$

Reference [4] recommends the use of seasonal autoregressive (SAR) and seasonal moving average (SMA) terms for monthly data with systematic seasonal movements. A SAR (p) term can be included in our equation specification for a seasonal autoregressive term with lag p. The lag polynomial used in estimation is the product of the one specified by the AR terms and the one specified by the SAR terms. The purpose of the SAR is to allow you to form the product of lag polynomials.

Similarly, SMA (q) can be included in our specification to specify a seasonal moving average term with lag q. The lag polynomial used in estimation is the product of the one defined by the MA terms and the one specified by the SMA terms. As with the SAR, the SMA term allows you to build up a polynomial that is the product of underlying lag polynomials.

Modeling power of monthly electrical peak of RIS and RIN, made by a SARIMA model is expressed in terms of the order of months, the maximal temperature and the minimal relative humidity and the terms of seasonality as well.

\subsection{Models for RIS}

The models used for modeling the monthly electrical peak of the Interconnected South (RIS) network are:

$$
\begin{gathered}
C_{t 1}=\alpha_{0}+\alpha_{1} T_{t}+\alpha_{2} H_{t}+\alpha_{3} M_{t}+u_{t} \\
C_{t 2}=\alpha_{0}+\alpha_{1} T_{t}+\alpha_{2} H_{t}+\alpha_{3} M_{t}+\alpha_{6} C_{i}+u_{t} \\
\ln \left(C_{t 3}\right)=\alpha_{0}+\alpha_{1} T_{t}+\alpha_{2} H_{t}+u_{t} \\
\ln \left(C_{t 4}\right)=\alpha_{0}+\alpha_{1} T_{t}+\alpha_{2} H_{t}+\alpha_{3} M_{t}+u_{t} \\
\ln \left(C_{t 5}\right)=\alpha_{0}+\alpha_{2} H_{t}+\alpha_{3} M_{t}+u_{t} \\
\ln \left(C_{t 6}\right)=\alpha_{0}+u_{t} \\
\ln \left(C_{t 7}\right)=\alpha_{0}+\alpha_{1} T_{t}+\alpha_{2} H_{t}+\alpha_{3} M_{t}+\alpha_{6} C_{i}+u_{t}
\end{gathered}
$$

Where:

$T_{t}$ is the temperature at month $\mathrm{t}$.

$H_{t}$ is the relative humidity at month $\mathrm{t}$.

$M_{t}$ is the order of the month ( 1 = January 2006 December $2006=12,13=$ January $2007=24$ December 2007).

$C_{i}$ is the average seasonal coefficient for each month. $u_{t}$ is white noise.

Where $\alpha_{0}$ and $\left(\alpha_{1}, \alpha_{2}, \alpha_{3}, \alpha_{4}, \alpha_{5}, \alpha_{6}, \alpha_{7}\right)$ are intercepted and regression coefficients, respectively. For handling serial correlation, we implement autoregressive in the error term of demand models. This usual method is expressed in equation (8). Here, autoregressive order two model is applied in the composed regression models. As options, models without and with autoregressive model of order one are computed as well.

$$
\begin{gathered}
u_{t}=\beta_{1} u_{t-1}+\beta_{2} u_{t-2}+\ldots+\beta_{P} u_{t-P}+\varepsilon_{t}=\beta_{1} \operatorname{sma}(12)+ \\
\beta_{2} \operatorname{sar}(12)+\varepsilon_{t}
\end{gathered}
$$


Where $u_{t}, \beta_{p}$ and $p$ are $\varepsilon_{t}$ error term, constant, autoregressive order, and a white noise, respectively. (sar(12)) and (sma(12)) are seasonal autoregressive and seasonal moving average terms for monthly respectively.

\subsection{Models for RIN}

The models used for modeling the monthly peak of North interconnected network (RIN) are:

$$
\begin{gathered}
C_{t 1^{\prime}}=\alpha_{0}+\alpha_{1} T_{t}+\alpha_{2} H_{t}+\alpha_{3} M_{t}+\alpha_{4} M_{t}^{2}+u_{t} \\
\left.C_{t 2^{\prime}}=\alpha_{0}+\alpha_{1} T_{t}+\alpha_{2} H_{t}+\alpha_{3} M_{t}+\alpha_{4} M_{t}^{2}+\alpha_{5} M_{t}^{3}+\alpha_{6} C_{i}+u_{t}\right) \\
\ln \left(C_{t 3 \prime}\right)=\alpha_{0}+\alpha_{1} T_{t}+\alpha_{2} H_{t}+u_{t} \\
\left.\ln \left(C_{t 4 \prime}\right)=\alpha_{0}+\alpha_{2} T_{t}+\alpha_{3} M_{t}+\alpha_{4} M_{t}^{2}+u_{t}\right) \\
\left.\ln \left(C_{t 5 \prime}\right)=\alpha_{0}+\alpha_{3} M_{t}+\alpha_{4} M_{t}^{2}+u_{t}\right) \\
\ln \left(C_{t 6 \prime}\right)=\alpha_{0}+u_{t} \\
\ln \left(C_{t 7 \prime}\right)=\alpha_{0}+\alpha_{1} T_{t}+\alpha_{2} H_{t}+\alpha_{3} M_{t}+\alpha_{4} M_{t}^{2}+ \\
\left.\alpha_{5} M_{t}^{3}+\alpha_{6} C_{i}+u_{t}\right)
\end{gathered}
$$

Where $\alpha_{0}$ and $\left(\alpha_{1}, \alpha_{2}, \alpha_{3}, \alpha_{4}, \alpha_{5}, \alpha_{6}, \alpha_{7}\right)$ are intercepted and regression coefficients, respectively. For handling serial correlation, we implement autoregressive in the error term of demand models. This usual method is expressed in equation (8'). Here, autoregressive order two model is applied in the composed regression models. As options, models without and with autoregressive model of order one are computed as well.

$$
\begin{gathered}
u_{t}=\beta_{1} u_{t-1}+\beta_{2} u_{t-2}+\ldots+\beta_{P} u_{t-P}+\varepsilon_{t}=\beta_{1} \operatorname{sma}(12)+ \\
\beta_{2} \operatorname{sar}(12)+\varepsilon_{t}
\end{gathered}
$$

\begin{tabular}{|c|c|c|c|c|c|}
\hline \multirow[b]{2}{*}{ variable } & \multicolumn{2}{|c|}{ Differentiation of order 0} & \multicolumn{2}{|c|}{ Differentiation of order 1} & \multirow[b]{2}{*}{ Résultats } \\
\hline & $\begin{array}{l}\text { p-value } \\
\text { PP.test }\end{array}$ & p-value ADF.test & $\begin{array}{l}\text { p-value } \\
\text { PP.test }\end{array}$ & $\begin{array}{l}\text { p-value } \\
\text { ADF.test }\end{array}$ & \\
\hline PRIS & 0.6665 & 0.9940 & 0.0000 & 0.0000 & $d=1$ \\
\hline Ln (PRIS) & 0.7657 & 0.7147 & 0.0000 & 0.0000 & $\mathrm{~d}=1$ \\
\hline TRIS & 0.0001 & 0.0001 & $*$ & * & $d=0$ \\
\hline HRIS & 0.0001 & 0.0001 & $*$ & * & $\mathrm{d}=0$ \\
\hline PRIN & 0.2572 & 0.9896 & 0.0000 & 0.0000 & $\mathrm{~d}=1$ \\
\hline LN(PRIN) & 0.2551 & 0.9787 & 0.0000 & 0.0000 & $\mathrm{~d}=1$ \\
\hline TRIN & 0.0108 & 0.9725 & $*$ & * & $\mathrm{d}=0$ \\
\hline
\end{tabular}

\begin{tabular}{|c|c|c|c|c|c|c|c|c|}
\hline \multirow{2}{*}{$\begin{array}{l}\text { Explanation } \\
\text { Variable }\end{array}$} & \multicolumn{2}{|l|}{ Model 1} & \multicolumn{2}{|l|}{ Model 2} & \multicolumn{2}{|l|}{ Model 3} & \multicolumn{2}{|l|}{ Model 4} \\
\hline & Coef. & $\begin{array}{l}\text { Prob. } \\
\text { (p-value) }\end{array}$ & Coef. & $\begin{array}{l}\text { Prob. } \\
\text { (p-value) }\end{array}$ & Coef. & $\begin{array}{l}\text { Prob. } \\
\text { (p-value) }\end{array}$ & Coef. & $\begin{array}{l}\text { Prob. } \\
\text { (p-value) }\end{array}$ \\
\hline \multirow{2}{*}{$\mathrm{T}_{\mathrm{t}}$} & 0.3244 & 0.9154 & 1.0178 & 0.5935 & -0.003 & 0.5654 & 0.0019 & 0.7233 \\
\hline & -3.0409 & $0.10670 *$ & -1.895 & $0.5369 *$ & -0.0052 & $-0.578^{*}$ & -0.0053 & $0.3558 *$ \\
\hline \multirow{2}{*}{$\mathrm{H}_{\mathrm{t}}$} & 0.0958 & 0.7074 & 0.2479 & 0.2609 & 0.0002 & 0.5146 & 0.0002 & 0.5376 \\
\hline & -0.2541 & $0.3773 *$ & -0.218 & $1.1364 *$ & -0.0004 & $0.6558 *$ & -0.0004 & $0.6204 *$ \\
\hline \multirow{2}{*}{$\mathrm{M}_{\mathrm{t}}$} & 36.4687 & 0.8307 & 3.20944 & 0 & & & 0.016 & 0.4012 \\
\hline & -169.768 & $0.2148^{*}$ & -0.21 & $15.2391 *$ & & & -0.019 & $0.8461 *$ \\
\hline \multirow{2}{*}{$\operatorname{SMA}(12)$} & -0.86034 & 0 & -0.8569 & 0 & -0.8815 & 0 & -0.8729 & 0 \\
\hline & -0.0348 & $-24.700 *$ & -0.052 & $-16.298 *$ & -0.0375 & $-23.45^{*}$ & -0.0361 & $-24.14 *$ \\
\hline \multirow{3}{*}{ SAR(12) } & 0.9902 & 0 & 0.3558 & 0.0355 & 0.9997 & 0 & 0.9706 & 0 \\
\hline & -0.0484 & $20.4274 *$ & -0.164 & $2.1579 *$ & -0.0312 & $31.997^{*}$ & -0.0454 & $21.375^{*}$ \\
\hline & -42031.82 & 0.9205 & -170.79 & 0.0122 & 251.479 & 0.9932 & 1.2211 & 0.9355 \\
\hline \multirow[t]{2}{*}{$\alpha_{0}$} & -419120 & $-0.1002 *$ & -65.8 & $-2.5955^{*}$ & -29512 & $0.0085 *$ & -15.03 & $0.0812 *$ \\
\hline & & & -535.3 & 0 & & & & \\
\hline $\mathrm{C}_{\mathrm{i}}$ & & & -53.29 & $10.0461 *$ & & & & \\
\hline
\end{tabular}

Where $u_{t}, \beta_{p}$ and $p$ are $\varepsilon_{t}$ error term, constant, autoregressive order, and a white noise, respectively. (sar(12)) and (sma(12)) are seasonal autoregressive and seasonal moving average terms for monthly respectively.

\section{Results}

Table 5. Results of $A D F$ and PP tests

Table 6. Regression coefficients for RIS 
Table 6 continued

\begin{tabular}{|c|c|c|c|c|c|c|}
\hline \multirow{2}{*}{$\begin{array}{l}\text { Explanation } \\
\text { Variable }\end{array}$} & \multicolumn{2}{|l|}{ Model 5} & \multicolumn{2}{|l|}{ Model 6} & \multicolumn{2}{|l|}{ Model 7} \\
\hline & Coef. & $\begin{array}{l}\text { Prob. } \\
\text { (p-value) }\end{array}$ & Coef. & $\begin{array}{l}\text { Prob. } \\
\text { (p-value) }\end{array}$ & Coef. & $\begin{array}{l}\text { Prob. } \\
\text { (p-value) }\end{array}$ \\
\hline \multicolumn{7}{|l|}{$\mathrm{T}_{t}$} \\
\hline \multirow{6}{*}{$\operatorname{SMA}(12)$} & 0.00026 & 0.5565 & & & 0.0004 & 0.1586 \\
\hline & -0.0004 & $0.5916^{*}$ & & & -0.0003 & $1.4297 *$ \\
\hline & 0.0153 & 0.3838 & & & 0.0054 & 0 \\
\hline & -0.0174 & $0.8780^{*}$ & & & -0.0002 & $27.0843^{*}$ \\
\hline & -0.8729 & 0 & -0.8807 & 0 & -0.8596 & 0 \\
\hline & -0.036 & $-24.22 *$ & -0.036 & $-24.16^{*}$ & -0.0476 & $-18.031 *$ \\
\hline \multirow{2}{*}{$\operatorname{SAR}(12)$} & 0.9718 & 0 & 0.9998 & 0 & 0.2444 & 0.1028 \\
\hline & -0.0433 & $22.425^{*}$ & -0.028 & $35.452 *$ & -0.1472 & $1.6594 *$ \\
\hline & 1.4342 & 0.9213 & 373.06 & 0.995 & 5.0819 & 0 \\
\hline$\alpha_{0}$ & -14.442 & $0.0993 *$ & -59237 & $0.0062 *$ & -0.0764 & $66.5018^{*}$ \\
\hline & & & & & 0.9603 & 0 \\
\hline $\mathrm{C}_{i}$ & & & & & -0.0613 & $15.662 *$ \\
\hline
\end{tabular}

() T-statistic, * adjs. standard error, _the related variable is not significant.

To determine the most appropriate model for our study, we firstly performed stationary tests (Augmented DickeyFuller (ADF) and Phillips-Perron (PP)) on the variables used. From these tests, we find that the meteorological variables (temperature and relative humidity) are stationary while the variable electrical peak is integrated at order 1 . Results of these tests are recorded in Table 5. So, we can apply the model of linear regression over time.

The different models used are those minimizing the Akaike (AIC) and Schwartz (SC) criteria. Tests Fisher and Student tests which are respectively global and individual significance of coefficients of various parameters are listed in Tables 6 and 7 From the analysis of the coefficients of the parameters, we can see that the coefficients of meteorological parameters are not significant because the $\mathrm{p}$-value of these variables are greater than the threshold $\alpha=$ $5 \%$.

After having removed these variables, we find that AIC and $\mathrm{SC}$ increases, meanwhile the best models are based on AIC and SC weak. Conclusively, we can say that the coefficients related to the temperature and the relative humidity is significant for our different models. Meteorological parameters thus influence the monthly peak $C_{t}$.

Table 7. Regression statistics of RIS

\begin{tabular}{|c|c|c|c|c|c|c|c|c|c|c|c|c|}
\hline \multirow{2}{*}{ Linear Models } & \multirow{2}{*}{$\mathbf{R}^{2}$} & \multirow{2}{*}{$\mathbf{R}^{2}$} & \multirow[b]{2}{*}{ SE Reg. } & \multirow{2}{*}{$\begin{array}{l}\text { Prob. } \\
\text { (F-Sta) }\end{array}$} & \multirow{2}{*}{ AIC } & \multirow{2}{*}{ SC } & \multicolumn{2}{|l|}{ White-test } & \multirow{2}{*}{$\begin{array}{l}\text { JB-test } \\
\text { (p-value) }\end{array}$} & \multirow[b]{2}{*}{ F-Stat } & \multicolumn{2}{|l|}{$\begin{array}{l}\text { B-D (LM) } \\
\text { D-W }\end{array}$} \\
\hline & & & & & & & $\begin{array}{l}\text { ORS } \\
\text { (p-value) }\end{array}$ & $\begin{array}{l}\text { F-stat } \\
\text { (p-value) }\end{array}$ & & & $\begin{array}{l}\text { ORS } \\
\text { (p-value) }\end{array}$ & $\begin{array}{l}\text { F-stat } \\
\text { (p-value) }\end{array}$ \\
\hline Model $1\left(C_{t 1}\right)$ & 0.9576 & 0.9537 & 11.9938 & 0.0000 & 7.9013 & 8.1107 & $\begin{array}{l}22.7978 \\
(0.5894)\end{array}$ & $\begin{array}{l}0.8334 \\
(0.6784)\end{array}$ & $\begin{array}{l}8.4332 \\
(0.0147)\end{array}$ & 244.2695 & $\begin{array}{l}3.0302 \\
(0.5528)\end{array}$ & $\begin{array}{l}0.6759 \\
(0.6118)\end{array}$ \\
\hline Model $2\left(C_{t 2}\right)$ & 0.9708 & 0.9675 & 10.0385 & 0.0000 & 7.5600 & 7.8043 & $\begin{array}{l}42.4642 \\
(0.1803)\end{array}$ & $\begin{array}{l}1.6605 \\
(0.0984)\end{array}$ & $\begin{array}{l}0.4018 \\
(0.8179)\end{array}$ & 294.5922 & $\begin{array}{l}1.8593 \\
(0.7616)\end{array}$ & $\begin{array}{l}0.5172 \\
(0.7234)\end{array}$ \\
\hline $\begin{array}{l}\text { Model } 3 \\
\left(\ln \left(C_{t 3}\right)\right)\end{array}$ & 0.9576 & 0.9545 & 0.0215 & 0.0000 & -4.7541 & -4.579 & $\begin{array}{l}11.8734 \\
(0.8910)\end{array}$ & $\begin{array}{l}0.5193 \\
(0.9368)\end{array}$ & $\begin{array}{l}5.0115 \\
(0.081)\end{array}$ & 310.7885 & $\begin{array}{l}1.8063 \\
(0.7713)\end{array}$ & $\begin{array}{l}0.5383 \\
(0.7082)\end{array}$ \\
\hline $\begin{array}{l}\text { Model } 4 \\
\left(\ln \left(C_{t 4}\right)\right)\end{array}$ & 0.9601 & 0.9564 & 0.0211 & 0.0000 & -4.7812 & -4.571 & $\begin{array}{l}23.1823 \\
(0.6752)\end{array}$ & $\begin{array}{l}0.7462 \\
(0.7794)\end{array}$ & $\begin{array}{l}5.5480 \\
(0.0624)\end{array}$ & 259.9912 & $\begin{array}{l}1.5936 \\
(0.8099)\end{array}$ & $\begin{array}{l}0.3638 \\
(0.8332)\end{array}$ \\
\hline $\begin{array}{l}\text { Model } 5 \\
\left(\ln \left(C_{t 5}\right)\right)\end{array}$ & 0.9600 & 0.9571 & 0.0209 & 0.0000 & -4.8122 & -4.637 & $\begin{array}{l}16.8179 \\
(0.6648)\end{array}$ & $\begin{array}{l}0.7594 \\
(0.7415)\end{array}$ & $\begin{array}{l}5.7856 \\
(0.0554)\end{array}$ & 330.2031 & $\begin{array}{l}1.5774 \\
(0.8128)\end{array}$ & $\begin{array}{l}0.3592 \\
(0.8364)\end{array}$ \\
\hline $\begin{array}{l}\text { Model } 6 \\
\left(\ln \left(C_{t 6}\right)\right)\end{array}$ & 0.9568 & 0.9553 & 0.0213 & 0.0000 & -4.8029 & -4.698 & $\begin{array}{l}6.1170 \\
(0.6341)\end{array}$ & $\begin{array}{l}0.7237 \\
(0.6698)\end{array}$ & $\begin{array}{l}4.2694 \\
(0.1182)\end{array}$ & 632.2619 & $\begin{array}{l}1.6126 \\
(0.8065)\end{array}$ & $\begin{array}{l}0.5974 \\
(0.6661)\end{array}$ \\
\hline $\begin{array}{l}\text { Model } 7 \\
\left(\ln \left(C_{t 7}\right)\right)\end{array}$ & 0.9743 & 0.9719 & 0.0169 & 0.0000 & -5.2209 & -5.011 & $\begin{array}{l}32.0468 \\
(0.2304)\end{array}$ & $\begin{array}{l}1.3587 \\
(0.2019)\end{array}$ & $\begin{array}{l}0.0738 \\
(0.9637)\end{array}$ & 409.5155 & $\begin{array}{l}1.1812 \\
(0.8812)\end{array}$ & $\begin{array}{l}0.2710 \\
(0.8953)\end{array}$ \\
\hline
\end{tabular}

() P-value

The coefficients of determination of the models of RIS and RIN are between (0.953 and 0.971) and (0.944 and 0.971) respectively and Prob (F-stat) is zero for these models. We can therefore conclude that our models are valid. We can also note that the application of the variable logarithm $C_{t} \mathrm{C}$ allows us to have an $\mathrm{AIC}$ and a $\mathrm{SC}$ even lower. The introduction of seasonal coefficient $C_{i}$ allows us to have the best model for both networks.

For RIS model, we have following graphs : (B) forecast series in blue and forecast intervals to $95 \%$ in red (A) observation series in red, forecast series in green and residue in blue); 


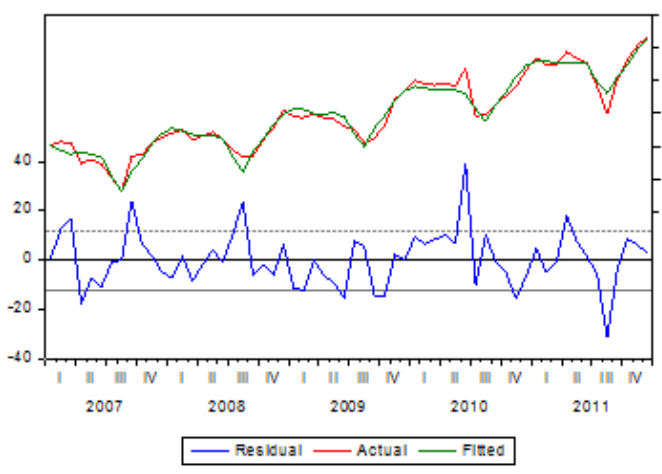

(A)

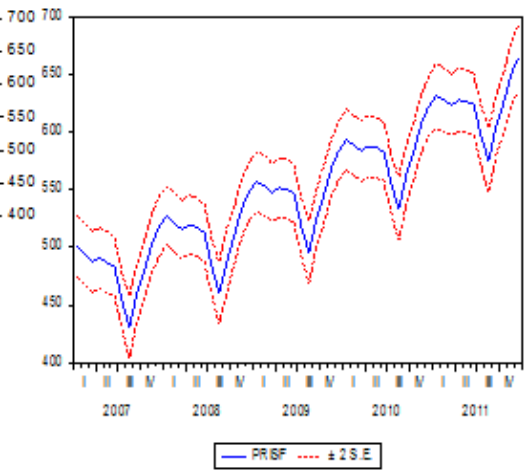

(B)

Figure 8. Model 1

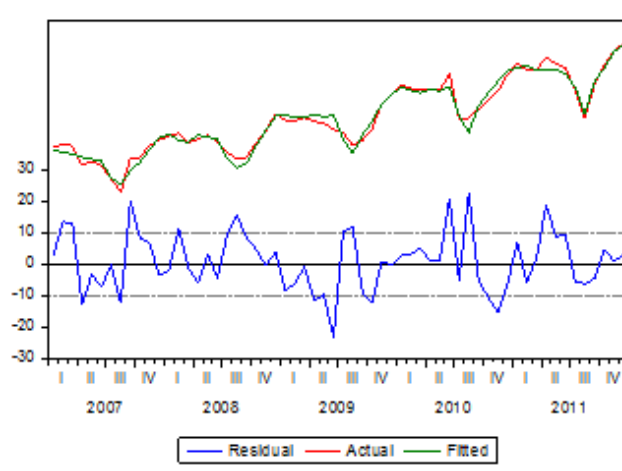

(A)

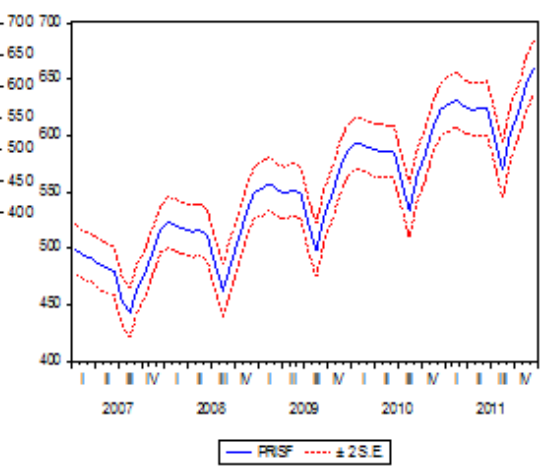

(B)

Figure 9. Model 2

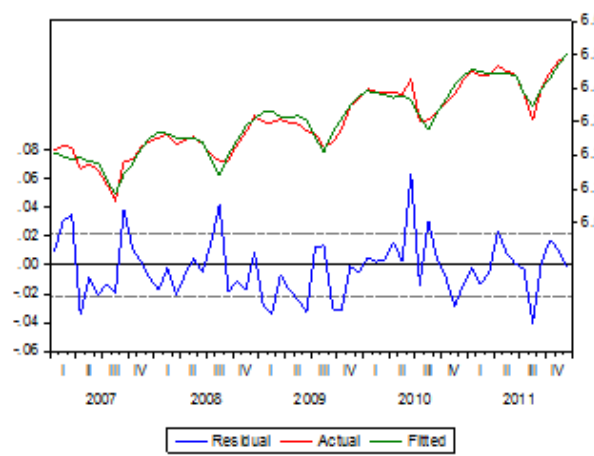

(A)

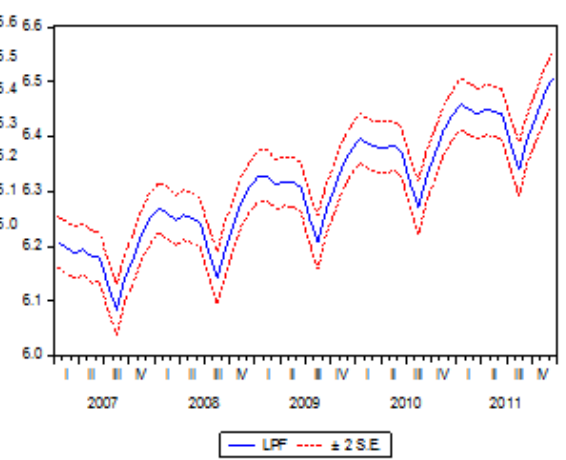

(B)

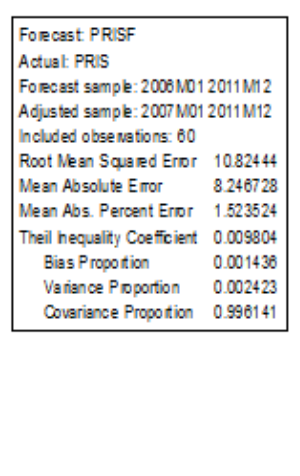

Actuat PRIS

tampe 2008 M01 2011/1/2 $012011 \mathrm{M} 12$

an Absolute Emor 8.246728 Wean Abs. Percent Eror 1.523524 Bias Propotion 0.00143 Variance Proportion $\quad 0.002423$ Covariance Propotion 0.996141

\section{Forecast: PRISF}

Actual: PRIS

Forecast sample: 2006M01 2011M12 Adjusted sample: 2007/N01 2011M12 Included obs enstions: 60

Root Mean Squared Emor $\quad 10.57622$ Mean Absolute Eror $\quad 8.301528$ Nenn Abs. Perent Emor 1.523858 Thei l hequality Coefficient 0.009592 Bas Proportion 0003921 Varine Popotion 0.01284 \begin{tabular}{ll} 
Covariance Proportion & 0.983730 \\
\hline
\end{tabular} 


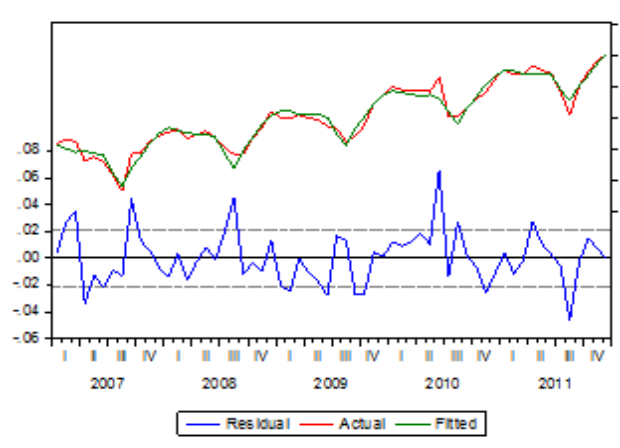

(A)

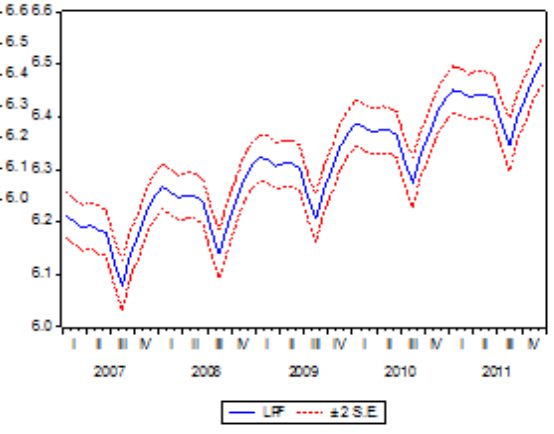

(B)

Figure 12. Model 5

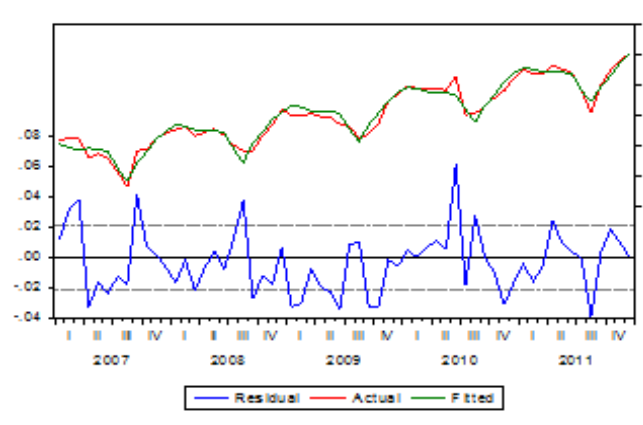

(A)

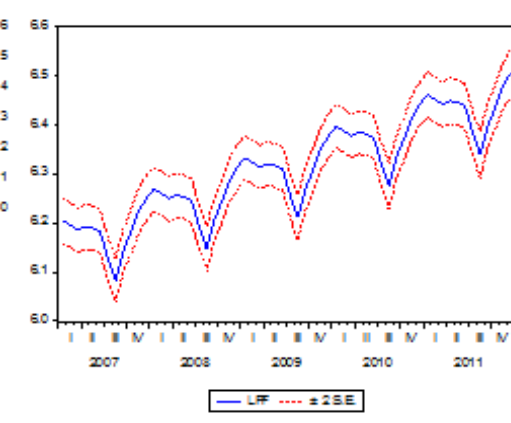

(B)

Figure 13. Model 6

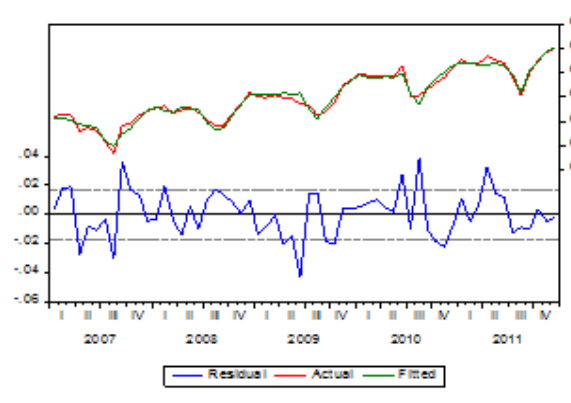

(A)

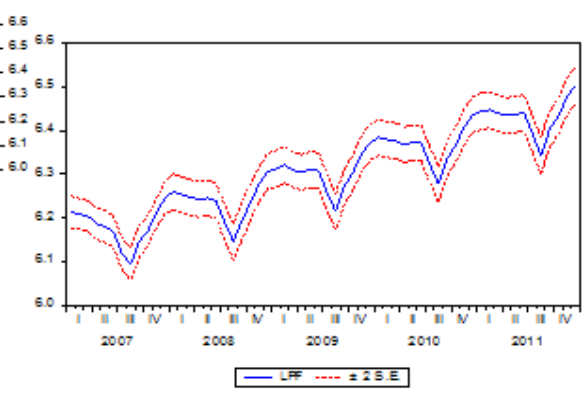

(B)
Forecast: LPF

Actuat: LP

Forecast sampe: 2008M01 2011M12 Adjus ted sampe: 2007/M01 201 1M12 hcluded obsenations: 60

Foot Mean Squared Emor 0.01932 Mean Absolute Emor $\quad 0.014811$ Mean Abs. Percent Emor 0.23568 Theil hequa ity Coefficient 0.001532 Bias Propotion $\quad 0.001721$ \begin{tabular}{ll} 
Variance Propotion & 0.001673 \\
Covariance Proportion & 0.996606 \\
\hline
\end{tabular}
Forecast: LPF

Foseast sa molec 2008M01 $20111 \mathrm{M} 12$ Adusted s ample: 2007M01 2011M/2 holuded obsenasions 60 Root Nean Squased Error 0.020057 Mean Absolte Emor $\quad 0.015620$ Wean Abs. Pencent Error 0.248813 Bas Proportion 0.029468 Varance Proportion 0.000676

Figure 14. Model 7

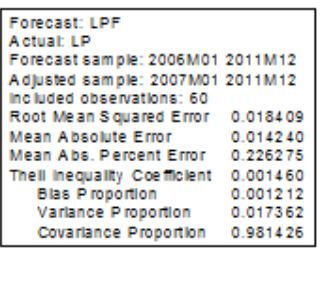

Table 8. Regression coefficients for RIN

\begin{tabular}{|c|c|c|c|c|c|c|c|c|}
\hline \multirow[b]{2}{*}{$\begin{array}{l}\text { Explanation } \\
\text { Variable }\end{array}$} & \multicolumn{2}{|l|}{ Model 1' } & \multicolumn{2}{|l|}{ Model 2' } & \multicolumn{2}{|l|}{ Model 3' } & \multicolumn{2}{|l|}{ Model 4' } \\
\hline & Coef. & $\begin{array}{l}\text { Prob.(p- } \\
\text { value) }\end{array}$ & Coef. & Prob.(p-value) & Coef. & $\begin{array}{l}\text { Prob.(p- } \\
\text { value) }\end{array}$ & Coef. & Prob.(p-value) \\
\hline \multirow[b]{2}{*}{$\mathrm{T}_{\mathrm{t}}$} & -0.2333 & 0.0911 & -0.1382 & 0.0859 & -0.0057 & 0.0708 & -0.00595 & 0.0817 \\
\hline & -0.1355 & $-1.721 *$ & -0.0781 & $-1.752 *$ & -0.0031 & $-1.843 *$ & -0.0033 & $-1.7755^{*}$ \\
\hline \multirow{2}{*}{$\mathrm{M}_{\mathrm{t}}$} & 27.6491 & 0.5284 & -0.5636 & 0.0883 & & & 0.430044 & 0.3573 \\
\hline & -43.557 & $0.6347 *$ & -0.3241 & $-1.7386^{*}$ & & & -0.463 & $0.9287 *$ \\
\hline \multirow{2}{*}{$\mathrm{M}_{\mathrm{t}}^{2}$} & -0.0546 & 0.2932 & 0.0195 & 0.0101 & & & -0.0011 & 0.1507 \\
\hline & -0.0514 & $-1.061^{*}$ & -0.0073 & $2.6735^{*}$ & & & -0.0007 & $-1.458^{*}$ \\
\hline $\mathrm{M}_{\mathrm{t}}^{3}$ & & & $\begin{array}{l}-0.0001 \\
-520 \mathrm{~F}-05\end{array}$ & 0.0052 & & & & \\
\hline \multirow{2}{*}{$\operatorname{SMA}(12)$} & -0.8567 & 0 & -0.8628 & 0 & -0.8816 & 0 & -0.8748 & 0 \\
\hline & -0.0404 & $-21.16^{*}$ & -0.0422 & $-20.413 *$ & -0.0345 & $-25.55^{*}$ & -0.0388 & $-22.51 *$ \\
\hline \multirow{2}{*}{ SAR(12) } & 0.9439 & 0 & 0.07307 & 0.6039 & 0.9296 & 0 & 0.9234 & 0 \\
\hline & -0.0454 & $20.746^{*}$ & -0.1399 & $0.52207 *$ & -0.0472 & $19.666^{*}$ & -0.0423 & $21.827 *$ \\
\hline \multirow{2}{*}{$\mathrm{AR}(1)$} & 0.4389 & 0.0021 & 0.17491 & 0.242 & 0.6185 & 0 & 0.3985 & 0.0057 \\
\hline & -0.1352 & $3.2453 *$ & -0.1477 & $1.18411^{*}$ & -0.103 & $5.987 *$ & -0.1383 & $2.880^{*}$ \\
\hline \multirow[b]{2}{*}{$\alpha_{0}$} & -5760.9 & 0.6777 & 3.10168 & 0.5219 & 4.7285 & 0 & -62.1448 & 0.5609 \\
\hline & -13783 & $-0.417 *$ & -4.8094 & $0.6449 *$ & -0.666 & $7.099 *$ & -106.181 & $-0.585 *$ \\
\hline \multirow{2}{*}{$\mathrm{C}_{\mathrm{i}}$} & & & 40.6466 & 0 & & & & \\
\hline & & & -3.3255 & $12.2225^{*}$ & & & & \\
\hline
\end{tabular}


Table 8. continued

\begin{tabular}{|c|c|c|c|c|c|c|}
\hline \multirow{2}{*}{$\begin{array}{l}\text { Explanation } \\
\text { Variable }\end{array}$} & \multicolumn{2}{|l|}{ Model 5' } & \multicolumn{2}{|l|}{ Model 6' } & \multicolumn{2}{|l|}{ Model 7' } \\
\hline & Coef. & Prob.(p-value) & Coef. & Prob.(p-value) & Coef. & Prob.(p-value) \\
\hline \multirow{2}{*}{$\mathrm{T}_{\mathrm{t}}$} & & & & & -0.0038 & 0.0831 \\
\hline & & & & & -0.0021 & $-1.7681 *$ \\
\hline \multirow{2}{*}{$\mathrm{M}_{\mathrm{t}}$} & 0.16109 & 0.1611 & & & -0.01415 & 0.1908 \\
\hline & -0.1133 & $1.4212 *$ & & & -0.0106 & $-1.3261 *$ \\
\hline \multirow{2}{*}{$\mathrm{M}_{\mathrm{t}}^{2}$} & -0.0006 & 0.0648 & & & 0.00048 & 0.0396 \\
\hline & -0.0003 & $-1.885^{*}$ & & & -0.0002 & $2.1133^{*}$ \\
\hline \multirow{2}{*}{$\mathrm{M}_{\mathrm{t}}^{3}$} & & & & & $-3.72 \mathrm{E}-06$ & 0.0215 \\
\hline & & & & & $-1.50 \mathrm{E}-06$ & $-2.3742 *$ \\
\hline \multirow{2}{*}{$\operatorname{SMA}(12)$} & 0.1409 & 0 & -0.892 & 0 & -0.88211 & 0 \\
\hline & -2.6045 & $2.6045^{*}$ & 0.03549 & -25.134 & -0.0374 & $-23.577 *$ \\
\hline \multirow{2}{*}{$\operatorname{SAR}(12)$} & 0.8712 & 0 & 0.88485 & 0 & 0.1717 & 0.1638 \\
\hline & -0.0453 & $19.209^{*}$ & 0.05184 & 17.0662 & -0.1215 & $1.4130 *$ \\
\hline \multirow{3}{*}{$\operatorname{AR}(1)$} & 0.36702 & 0.0119 & 0.58696 & 0 & 0.21152 & 0.168 \\
\hline & -0.1409 & $2.6045^{*}$ & 0.10831 & 5.41891 & -0.1511 & $1.3990 *$ \\
\hline & -11.066 & 0.4605 & 4.17269 & 0 & 2.80242 & 0 \\
\hline$\alpha_{0}$ & -14.885 & $-0.743 *$ & 0.23605 & 17.6765 & -0.16911 & $16.5710^{*}$ \\
\hline \multirow{2}{*}{$\mathrm{C}_{\mathrm{i}}$} & & & & & 0.99491 & 0 \\
\hline & & & & & -0.0922 & $10.7894 *$ \\
\hline
\end{tabular}

() t-statistic, *adjs. standard error, _ the related variable is not significant

To verify the absence of autocorrelation of residues for the different models, we conducted the Breusch-Godfrey test $(\mathrm{BG})$ on all models because in these models we have use endogenous variable delayed among the exogenous variables by introducing the terms SMA (12) and SAR (12). Residues are correlated with the threshold $\alpha=5 \%$ if Pvalue $<0.05$. The analysis of test $\mathrm{BG}$ to order 4 and the threshold $\alpha=5 \%$, shows that P-value $>0.05$ for all models. We can therefore accept the hypothesis of no autocorrelation of residues for all models. The test of White (1980) applied to these models allow us to accept the hypothesis of no heteroscedasticity of errors for, the threshold $\alpha=5 \%$, P-value $>0.05$. Our residue being homoscedastic it is a white noise. The results of these tests are listed in Tables 8 and 9.

To know whether our white noise is Gaussian, we performed the Jarque-Bera test (JB). The hypothesis of obtaining a Gaussian white noise is true at the threshold $\alpha=$ $5 \%$, if the Jarque-Bera statistic is greater than the one read from the table of chi-square (JB stat $<5.99$ ) and the probability of the Jarque-Bera statistic provided by Eviews is below the defined threshold (P-value $>5 \%)$. The analysis of this test allows us to accept the hypothesis of a Gaussian white noise for all models except Model 1 not which does not fulfilled the conditions of Gaussian white noise because $\mathrm{JB}$ stat $=8.4332>599$ and P-value $=0.0147<0.05$. The results of the various tests are listed in Tables 8 and 9 .

Table 9. Regression statistics of RIN

\begin{tabular}{|c|c|c|c|c|c|c|c|c|c|c|c|c|}
\hline \multirow{2}{*}{ Linear Models } & \multirow{2}{*}{$\mathbf{R}^{2}$} & \multirow{2}{*}{$\mathbf{R}^{2}$} & \multirow{2}{*}{ SE Reg. } & \multirow{2}{*}{$\begin{array}{l}\text { Prob. } \\
\text { (F-Sta) }\end{array}$} & \multirow{2}{*}{ AIC } & \multirow{2}{*}{ SC } & \multicolumn{2}{|l|}{ White-test } & \multirow{2}{*}{$\begin{array}{l}\text { JB-test } \\
\text { (p-value) }\end{array}$} & \multirow{2}{*}{ F -Stat } & \multicolumn{2}{|l|}{$\begin{array}{l}\text { B-D (LM) } \\
\text { D-W }\end{array}$} \\
\hline & & & & & & & $\begin{array}{l}\text { ORS } \\
\text { (p-value) }\end{array}$ & $\begin{array}{l}\text { F-stat } \\
\text { (p-value) }\end{array}$ & & & $\begin{array}{l}\text { ORS } \\
\text { (p-value) }\end{array}$ & $\begin{array}{l}\text { F- stat } \\
\text { (p-value) }\end{array}$ \\
\hline Model 1' $\left(C_{t 1}^{\prime}\right)$ & 0.9503 & 0.9446 & 0.9290 & 0.0000 & 2.8017 & 3.0482 & $\begin{array}{l}34.0937 \\
(0.3672)\end{array}$ & $\begin{array}{l}1.1122 \\
(0.394)\end{array}$ & $\begin{array}{l}0.4474 \\
(0.7996)\end{array}$ & 166.026 & $\begin{array}{l}3.24199 \\
(0.5182)\end{array}$ & $\begin{array}{l}0.69939 \\
(0.5962)\end{array}$ \\
\hline Model $2\left(C_{t 2}{ }^{\prime}\right)$ & 0.9744 & 0.9703 & 0.6804 & 0.0000 & 2.2073 & $\begin{array}{l}2.5242 \\
9\end{array}$ & $\begin{array}{l}54.7319 \\
(0.4086)\end{array}$ & $\begin{array}{l}1.2097 \\
(0.4635)\end{array}$ & $\begin{array}{l}1.6930 \\
(0.4289\end{array}$ & 238.034 & $\begin{array}{l}2.461882 \\
(0.6515)\end{array}$ & $\begin{array}{l}0.500755 \\
(0.7353)\end{array}$ \\
\hline $\begin{array}{l}\text { Model 3' } \\
\left(\ln \left(C_{t 3}^{\prime}\right)\right)\end{array}$ & 0.9499 & 0.9461 & 0.0231 & 0.0000 & - & $-\overline{4.4352}$ & $\begin{array}{l}17.1471 \\
(0.6434)\end{array}$ & $\begin{array}{c}0.7784 \\
(0.721)\end{array}$ & $\begin{array}{l}0.5353 \\
(0.7651)\end{array}$ & 255.959 & & $\begin{array}{l}0.55424 \\
(0.6968)\end{array}$ \\
\hline $\begin{array}{l}\text { Model 4' } \\
\left(\ln \left(C_{t 4}^{\prime}\right)\right)\end{array}$ & 0.9547 & 0.9495 & 0.0224 & 0.0000 & - & - & $\begin{array}{l}32.0447 \\
(0.4645)\end{array}$ & $\begin{array}{l}0.9659 \\
(0.5418)\end{array}$ & $\begin{array}{l}0.7031 \\
(0.7035)\end{array}$ & 182.8579 & $\begin{array}{l}1.46804 \\
(0.8323)\end{array}$ & $\begin{array}{l}0.30679 \\
(0.8720)\end{array}$ \\
\hline $\begin{array}{l}\text { Model 5, } \\
\left(\ln \left(C_{t 5}^{\prime}\right)\right)\end{array}$ & 0.9526 & 0.9481 & 0.0227 & 0.0000 & - & $-\overline{4.4224}$ & $\begin{array}{l}36.1437 \\
(0.0891)\end{array}$ & $\begin{array}{l}1.9462 \\
(0.0371)\end{array}$ & $\begin{array}{l}1.2144 \\
(0.5448)\end{array}$ & 213.2253 & $\begin{array}{l}2.53024 \\
(0.6392)\end{array}$ & $\begin{array}{l}0.54889 \\
(0.7007)\end{array}$ \\
\hline $\begin{array}{l}\text { Model 6' } \\
\left(\ln \left(C_{t 6}^{\prime}\right)\right)\end{array}$ & 0.9473 & 0.9444 & 0.0235 & 0.0000 & - & - & $\begin{array}{l}15.78257 \\
(0.3268)\end{array}$ & $\begin{array}{l}1.1477 \\
(0.3470)\end{array}$ & $\begin{array}{l}0.7154 \\
(0.6992)\end{array}$ & 176.3218 & $\begin{array}{l}0.7129 \\
(0.9497)\end{array}$ & $\begin{array}{l}0.6889 \\
(0.6030)\end{array}$ \\
\hline $\begin{array}{l}\text { Model 7' } \\
\left(\ln \left(C_{t 7}\right)\right)\end{array}$ & 0.9754 & 0.9715 & 0.0168 & 0.0000 & $\begin{array}{l}- \\
5.1890\end{array}$ & - & $\begin{array}{l}56.3379 \\
(0.3512)\end{array}$ & $\begin{array}{l}1.9965 \\
(0.2258)\end{array}$ & $\begin{array}{l}1.2724 \\
(0.5290)\end{array}$ & 248.3225 & $\begin{array}{l}1.75405 \\
(0.7809)\end{array}$ & $\begin{array}{l}0.35392 \\
(0.8400)\end{array}$ \\
\hline
\end{tabular}

() p-value 
For RIN model, we have the following graphs : (B) forecast series in blue and forecast intervals to $95 \%$ in red
(A) observation series in red, forecast series in green and residue in blue) ;

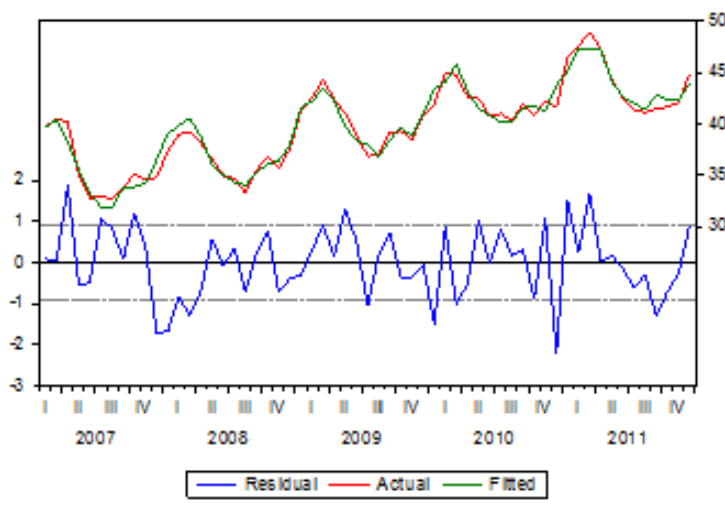

(A)

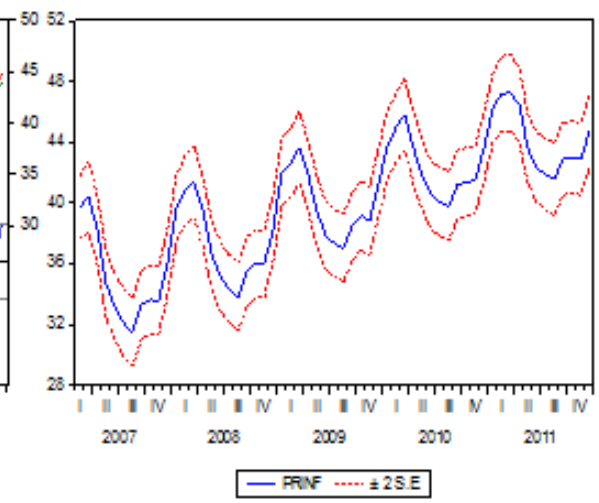

(B)

Figure 15. Model 1'

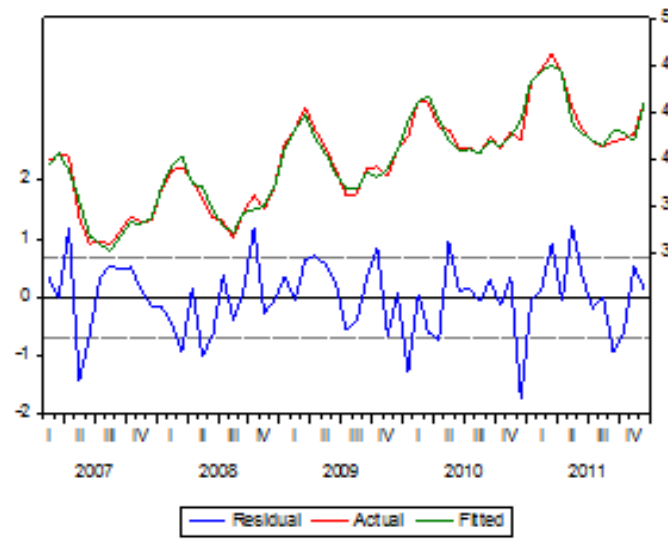

(A)

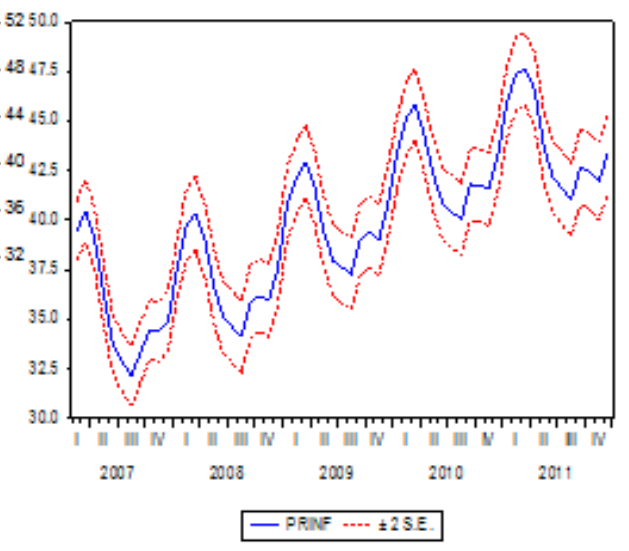

(B)

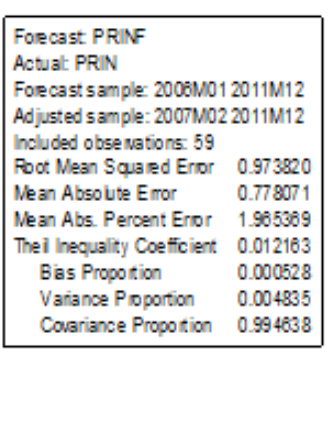

ast PRIN

Forecast s ample: 2006M01 $2011 \mathrm{M} 12$ Adjusted sample 2007N022011M12

Foot Mean Squared Eror 0.973820

Wean Abso ute Eror $\quad 0.778071$

A A E Eront Eror 1985389

Bas Propotion 0.000528 Varanoe Proportion $\quad 0.004835$

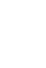

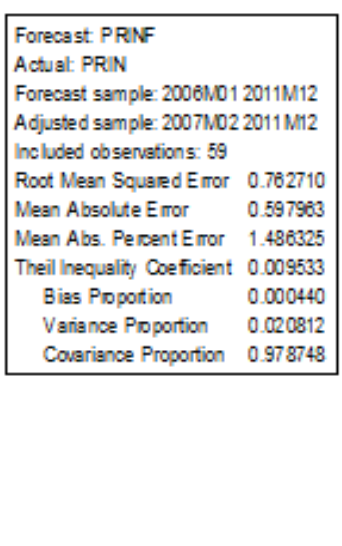

included obsenvtions: 59

Root Mean Squared Emor 0.762710

Mean A bsolute E mor $\quad 0.597963$

Til hequality Coeficient 0.009533

Biss Propotion $\quad 0.000440$

Variance Prportion 0.020812

Covariance Proportion 0.978748

Figure 16. Model 2'

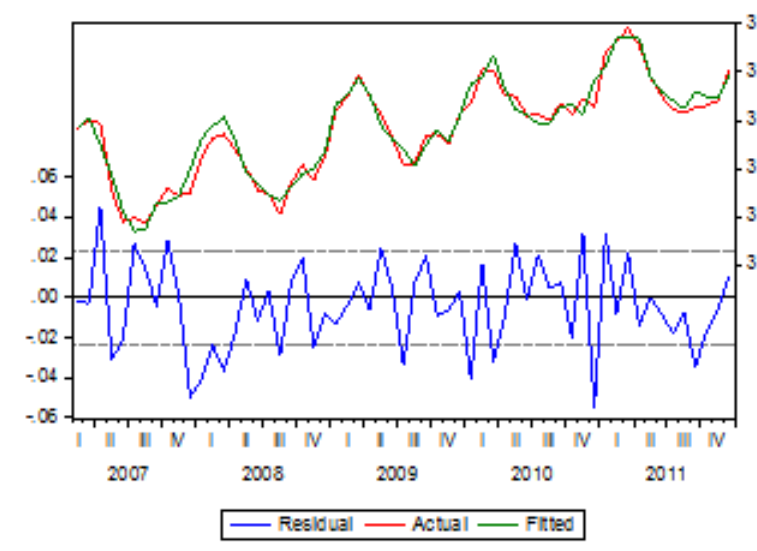

(A)

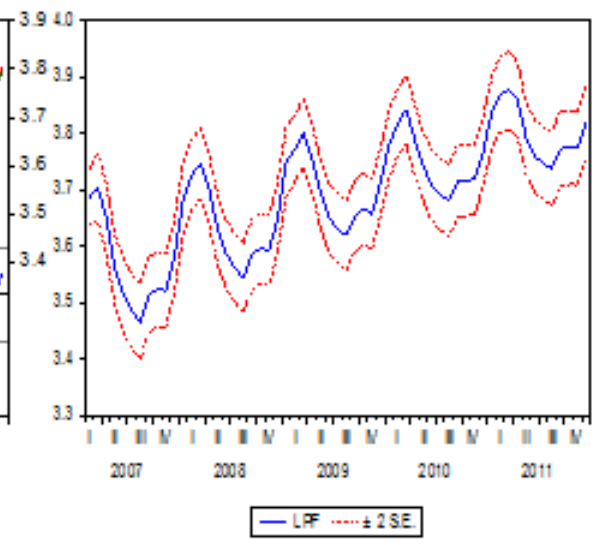

(B)

Figure 17. Model 3,

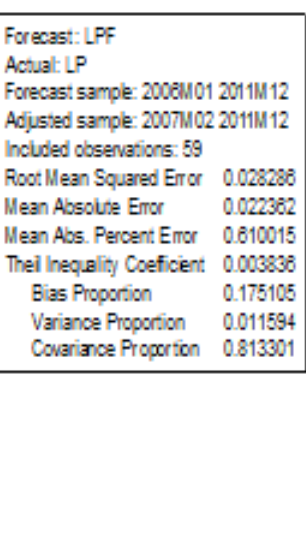

Forecast sample: 2000M01 2011M 12 $2007 M 022011412$

incuded ooservations: 59

Root Mean Squared Er or 0.028286 0.022502

Theil hepalih Coeficent 0,003836

Bias Proporion $\quad 0.175105$ Variance Proporion 0.011594

Covarisnoe Proportion 0.813301 


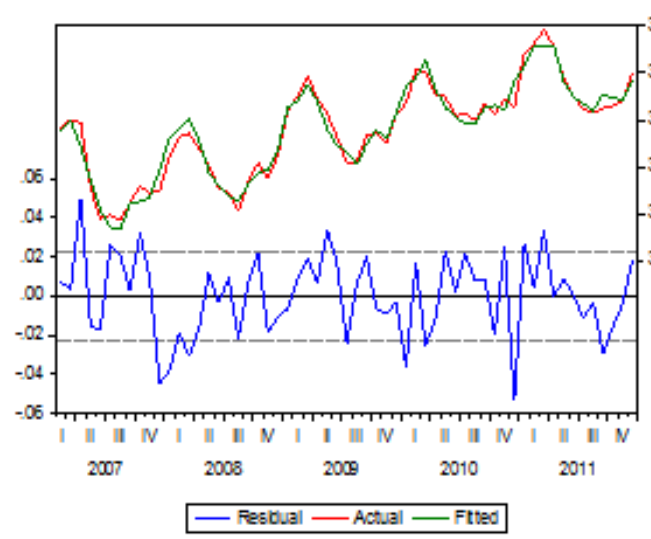

(A)

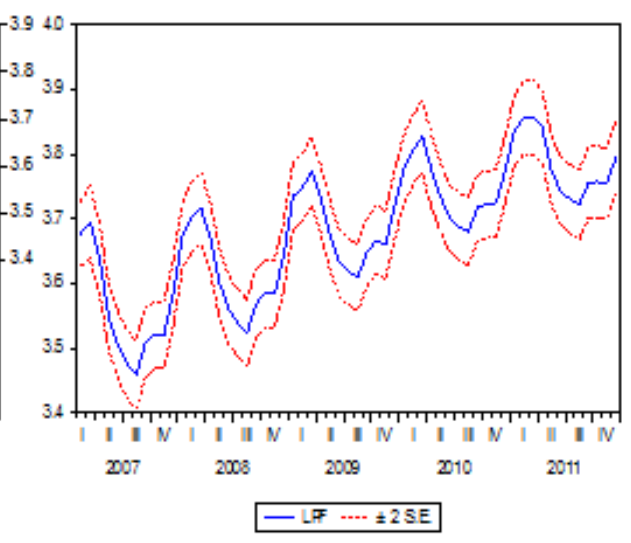

(B)

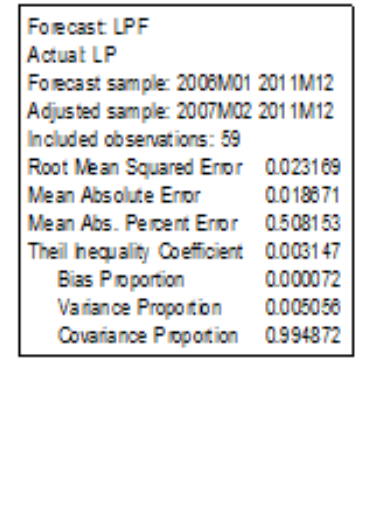

Figure 18. Model 4'

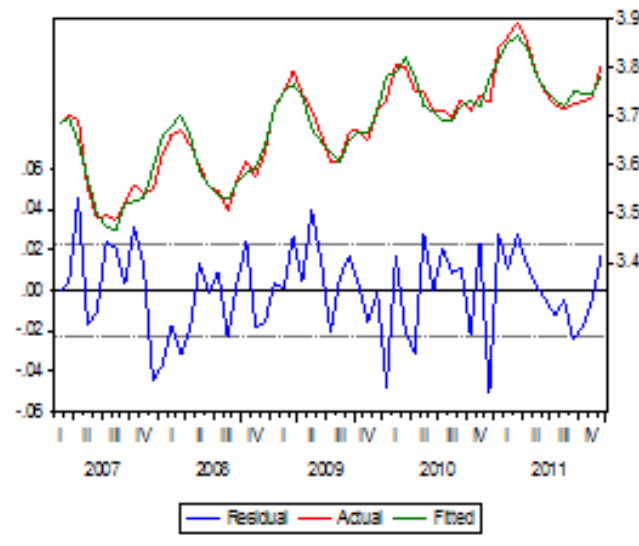

(A)

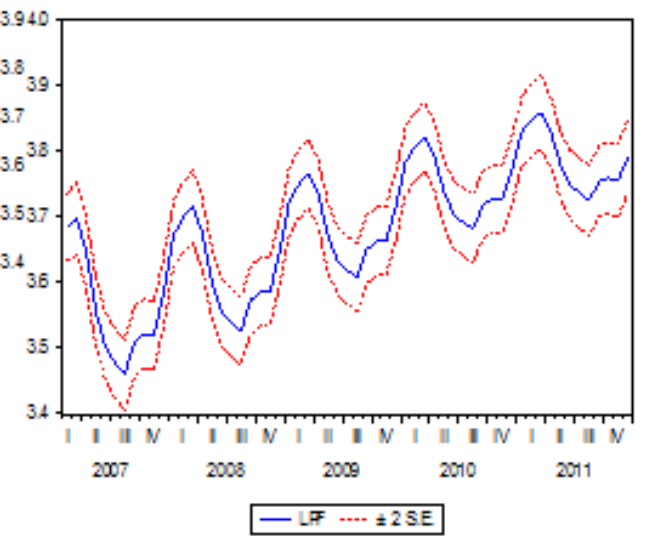

(B)

Figure 19. Model 5',

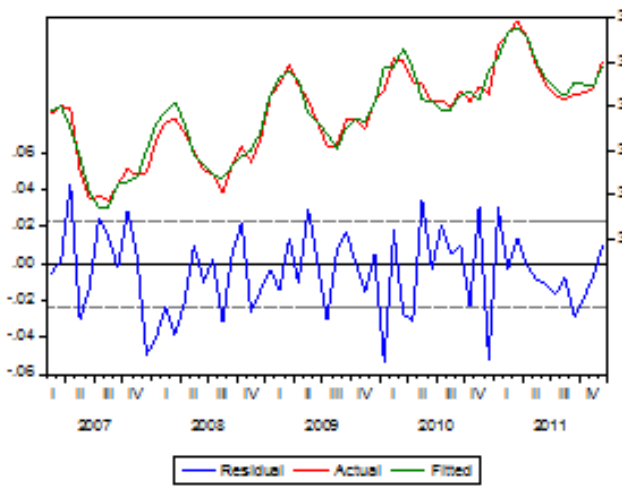

(A)

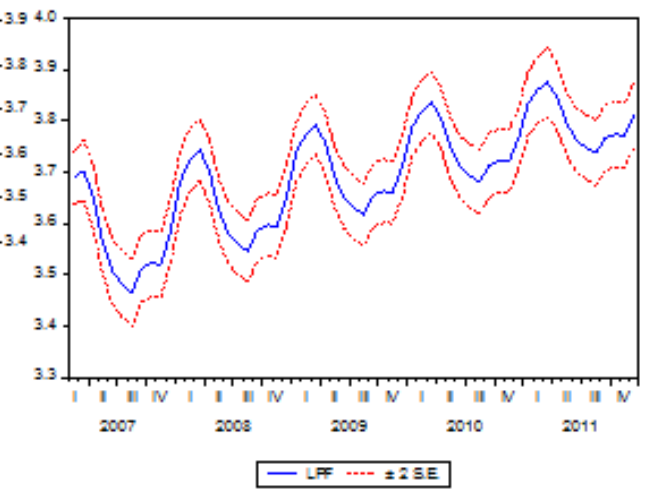

(B)

\section{Forecast LPF}

Actual LP

Fo recast sample: 2008 M012011 M12 Adjusted sample: 2007 MO2 2011M12 holuded obse vations: 59

Root Mean Squared Emor 0.023491 Mean Absolute Eror $\quad 0.018846$ Mean Abs. Pecent Eror $\quad 0.512111$ Theil hequality Coeficient 0.003191

Bias Propotion $\quad 0.000039$

Variance Proportion $\quad 0.001881$ Covariance Propotion 0.998080
Forecast: LPF

Actual: IP

Forecast sample: 2006M01 2011M12 Adusted sample 2007M02 2011M12 Included observations: 59

Root Mean Squared Error 0.028081 Mean Absolute Error $\quad 0.022328$ Mean Abs. Percent Emor 0.608987 Theil Inequaity Coeficient 0.003809 Bias Proportion $\quad 0.143390$ Varianoe Proportion 0.009758 $\begin{array}{ll}\text { Covaniance Proportion } & 0.848854\end{array}$ 


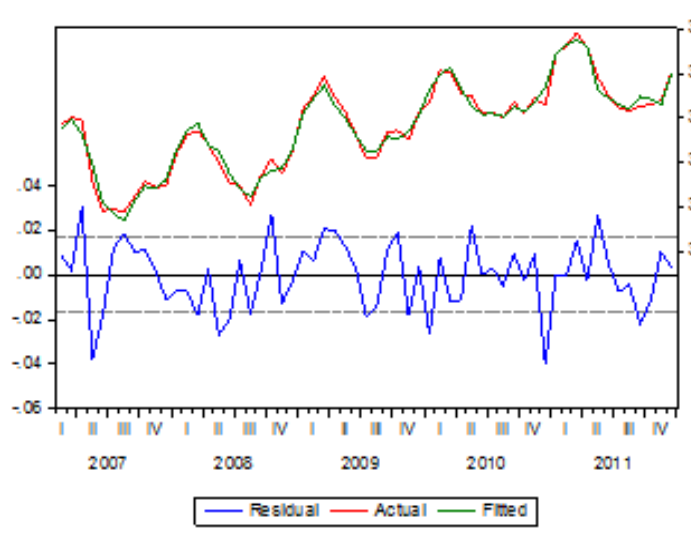

(A)

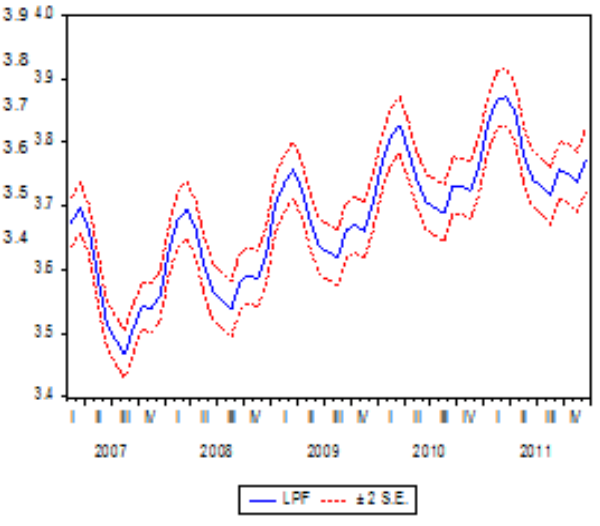

(B)

Figure 21. Model 7'

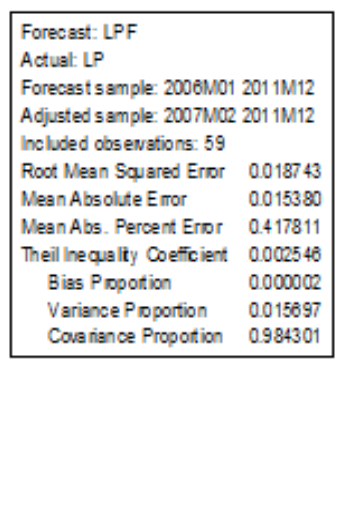

\section{Conclusion and Comments}

This study presents the modeling of the electricity monthly peak consumption of the main interconnected Cameroon namely the interconnected South (RIS) and North (RIN), using econometric techniques notably linear regression model networks. Meteorological parameters are considered as explanatory variables. We also noted that the application of the logarithm to the variable allows us to have an AIC and an even lower SC. The introduction of seasonal coefficient $c_{i}$ allows us to have the best model for both networks.

With the coming of this analysis, we note that meteorological parameters play a key role in the electricity monthly peak consumption in Cameroon. This is justified by the maxima and minima observed respectively in the dry and rainy season in both networks. Although the two areas do not have the same climate, the minimum of electricity monthly peak is observed during the month of August which is the wettest month in the country and also the month of holidays in several companies. The maximum observed in December for the RIS, this can be justified by the use of air conditioners and fans because of the heat caused by the onset of the dry season, but especially the preparations for the Christmas party and end year ceremonies. It should be noted that much of the population in the RIS area is Christian, so it gives a particular importance to the Christmas party. The use of garlands and bright decorations could also justify the high demand during this period. The strong demand of electricity in the RIS area can also be justified by the presence of political capital (Yaoundé) and economic (Douala) in this area. Large industries, departments and universities are also grouped in the majority in this area. December being the last month of the year and the month of heavy consumption of products; many companies increase their production to meet the high demand for this period. The closure of the financial year being also done in December, several companies must take stocks and develop strategies for the New Year. This requires extra works days or hours. This causes an increase in hours of work and resources leading to the use of additional electricity period consumption.

In the RIN, the electricity monthly peak consumption is generally observed in March and February. These two months correspond to the warmest months in this area. Refrigerators, freezers, Fans and air conditioners are stretched to their highest capacities because of the sweltering heat during this period. We also notice that the coefficients related to seasonality are highly significant in all models. This is due to climate variations that make the electrical monthly peak to be seasonal.

\section{Acknowledgements}

The authors thank Demsong Bethin for his help in the translation. We would like to express our sincere gratitude to the anonymous reviewers and the Editor of the Journal for many valuable comments.

\section{References}

[1] AES - SONEL ,2011 Rapport AES/AREVA.

[2] Annuaire statistique $2010 \mathrm{du}$ Cameroun - INS et Document de Stratégie pour la Croissance et l'Emploi- Rapport Définitif - Août 2009.

[3] A. Pardo, V. Meneu and E. Valor, "Temperature and Seasonality Influences on Spanish Electricity Load," Energy Economics, Vol. 24, pp. 55-70, 2002.

[4] Box, George E. P. and Gwilym M. Jenkins (1976).Time Series Analysis: Forecasting and Control, Revised Edition, Oakland, CA: Holden-Day.

[5] C. Adjamagbo, P. Ngae, A. Vianouet V. Vigneron « Modélisation de la demande en énergie électrique au Togo » Revue des Energies Renouvelables Vol. 14 Nº1 (2011) 67 67.

[6] Context of Auto-Correlated Errors," Journal of the American Statistical Association, 64, 253-272.

[7] D. H. W. Li, J. C. Lam, and S. L. Wong, "Daylightingand Its Effects on Peak Load Determination," Energy, Vol. 30, pp. 1817-1831, 2005. 
[8] EViews. http://www.eviews.com

[9] Fair, Ray C. (1984). Specification, Estimation, and Analysis of Macroeconometric Models, Cambridge, MA: Harvard University Press.

[10] F. Egelioglu, A. A. Mohamad, and H. Guven, "Economic Variables and Electricity Consumption in Northern Cyprus," Energy, Vol. 26, pp. 355-362, 2001.

[11] Greene, William H. (2008). Econometric Analysis, 6th Edition, Upper Saddle River, NJ: Prentice-Hall.

[12] Hamilton, James D. (1994a). Time Series Analysis, Princeton University Press.

[13] Hayashi, Fumio. (2000). Econometrics, Princeton, NJ: Princeton University Press.

[14] Johnston, Jack and John Enrico DiNardo (1997). Econometric Methods, 4th Edition, New York: McGrawHill.

[15] M. A. Almeida, R. Schaeffer and E. L. La Rovere, "The Potential for Electricity Conservation and Peak Load Reduction in the Residential Sector of Brazil," Energy, Vol. 26, pp. 413-429, 2001.

[16] M. A. Momani, "Factors Affecting Electricity Demand in Jordan," Energy and Power Engineering, Vol. 5, No. 1, pp. 50-58, 2013.

[17] S. B. Sadineni, and R. F. Boehm, "Measurements and
Simulations for Peak Electrical Load Reduction in Cooling Dominated Climate,” Energy, Vol. 37, pp. 689-697, 2012.

[18] S. Dudhani, A. K. Sinha, and S. S. Inamdar, "Renewable Energy Sources for Peak Load Demand Management in India," Electrical Power and Energy Systems, Vol. 28, pp. 396-400, 2006

[19] Wadjamsse Beaudelaire Djezou, PhD, "Analyse des déterminants de l'efficacité énergétique dans l'espace UEMOA" European Scientific Journal April 2013 edition vol.9, No.12 ISSN: 1857 - 7881 (Print) e - ISSN 1857- 7431.

[20] Y. S. Akil, and H. Miyauchi, "Seasonal Regression Models for Electricity Consumption Characteristics Analysis," Engineering, Vol. 5, No. 1B, pp. 108-114, 2013.

[21] Yusri Syam Akil, Hajime Miyauchi. Seasonal Peak Electricity Demand Characteristics: Japan Case Study. International Journal of Energy and Power Engineering. Vol. 2, No. 3, 2013, pp. 136-142. doi: 10.11648/j.ijepe.20130203.18.

[22] SIE-Cameroon, 2009. Cameroon energy information system: Report 2009. Ministryof Energy and Water resources.

[23] SIE-Cameroon, 2010. Cameroon energy information system: Report 2010. Ministryof Energy and Water resources.

[24] R. Starts, EViews Illustrated for Version 7.2, 1st Ed., (2012) Micro Software, LLC, 2012. 